\title{
EUROPEAN ECONOMY
}

EUROPEAN COMMISSION DIRECTORATE-GENERAL FOR ECONOMIC AND FINANCIAL AFFAIRS

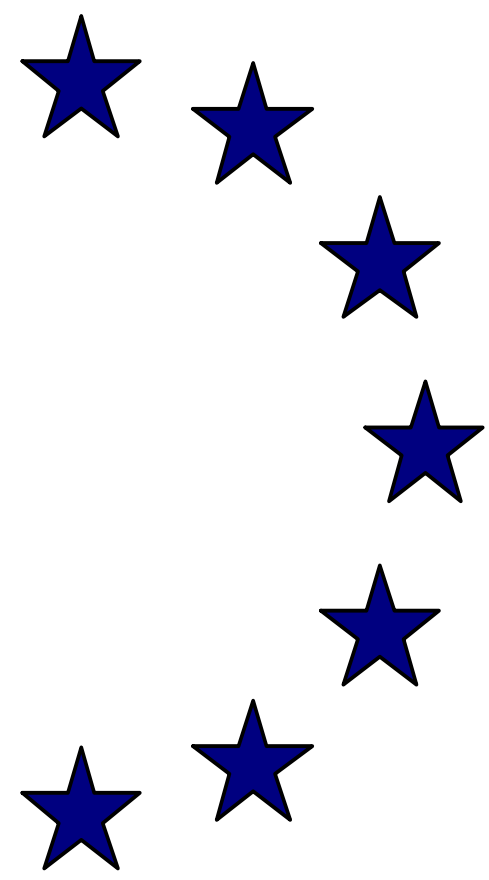

ECONOMIC PAPERS

ISSN 1725-3187

http://europa.eu.int/comm/economy finance

$N^{\circ} 201$

April 2004

Pension reforms: an illustrated basic analysis

by

Heikki Oksanen

Directorate-General for

Economic and Financial Affairs 
Economic Papers are written by the Staff of the Directorate-General for Economic and Financial Affairs, or by experts working in association with them. The "Papers" are intended to increase awareness of the technical work being done by the staff and to seek comments and suggestions for further analyses. Views expressed represent exclusively the positions of the author and do not necessarily correspond to those of the European Commission. Comments and enquiries should be addressed to the:

European Commission

Directorate-General for Economic and Financial Affairs

Publications

BU1 - $-1 / 180$

B - 1049 Brussels, Belgium

ECFIN/122/04-EN

ISBN 92-894-5966-2

KC-AI-04-201-EN-C

CEuropean Communities, 2004 


\title{
Pension Reforms: an illustrated basic analysis
}

\author{
by \\ Heikki Oksanen* \\ Directorate General for Economic and Financial Affairs \\ European Commission
}

\begin{abstract}
The paper examines pension reforms under ageing. Using stylised facts, ageing is traced to low fertility and increasing longevity. Given these persistent factors, pension systems must be reformed to avoid an unfair burden being left for future generations. The main results for reform blueprints are:

(1) In a Defined Benefit (DB) system, partial pre-funding is needed to achieve intergenerational fairness unless benefits are sufficiently reduced; partial privatisation is an option for the management of the accumulating funds.

(2) Transition from a DB to a Notional Defined Contribution (NDC) system is another reform option; it reduces the replacement rates to levels which match prescribed contribution rates; an NDC public pillar can be accompanied by a second pillar, managed by the private sector.

(3) An effective increase in the retirement age is necessary to moderate the increase in pension expenditure and to preserve adequate pension levels.

(4) Pension reforms have important effects on public finance target setting.
\end{abstract}

The illustrative simulations in the paper are based on Oksanen (2002) while Chapter 2 offers a new systematic analysis of the meaning and consequences of intergenerational fairness under population ageing.

JEL classification: H1, H5, H6

Keywords: Pension reform, pre-funding, privatisation, defined benefits, notional defined contribution system

\section{Acknowledgements:}

The author's special gratitude goes to Patrick Wiese of Actuarial Solutions LLC whose S-PRISM (Stylized Pension Reform Illustration and Simulation Model) was used for the simulations reported in this paper. I would like to thank Niels Kleis Frederiksen, Vincenzo Galasso, Juan Jimeno, Andràs Simonovits, two anonymous referees and many colleagues in DG ECFIN for comments which helped me to further clarify some of the arguments presented. Cecilia Mulligan, Sophie Bland (text) and Karel Havik (tables and graphs) deserve my warmest thanks for their careful editing work. I am solely responsible for remaining errors and omissions.

The views expressed are those of the author and do not necessarily reflect those of the European Commission.

This paper will also be published in CESifo Economic Studies, 3/2004 (http://www.cesifoeconomic-studies.de).

* Correspondence: Heikki.Oksanen@cec.eu.int. 


\section{TABLE OF CONTENTS}

1.1 The purpose of this paper 7

1.2 Agnosticism about arguments for funding in previous literature 9

2. Introducing fairness across generations under population ageing 12

2.1 An elementary analysis leading to partial funding and/or replacement $\begin{array}{ll}\text { rate reduction } & 12\end{array}$

2.2 A transition to Notional Defined Contribution (NDC) system 21

2.3 A Fully Funded Defined Contribution (FF DC) system 23

$\begin{array}{ll}2.4 \text { Retirement age increase and actuarial faimess } & 24\end{array}$

2.5 The thrust and limitations of the 3-period model 24

3. Reforms to a DB system illustrated with an actuarial model 27

$\begin{array}{ll}3.1 \text { The actuarial model } & 27\end{array}$

$\begin{array}{ll}3.2 \text { Base case assumptions } & 28\end{array}$

3.3 Pre-funding a DB system with fixed replacement rate and retirement age 29

3.4 Further reforms to a pre-funded DB system $\quad 32$

3.5 Partial privatisation of a pre-funded DB system 38

4. Transition to Notional Defined Contribution (NDC) system 43

5. Main implications for pension reforms and public finance 48

5.1 Comparison between DB and NDC reforms 48

5.2 Effects of pensions and ageing on public finance targets 52

6. Conclusions and main thrust of the present paper 54

$\begin{array}{ll}\text { References } & 59\end{array}$

Box 1 Derivation of the fair contribution rate under ageing: retirement age $60 \quad 30$

Box 2 Outcomes of the reforms with varying compensation for later retirement 38 
TABLES

Table 1 Scenarios for pension reforms under ageing population $\quad 19$

Table 2 A fully funded pension system under population ageing 20

Table 3 Reforming a Defined Benefit system 33

Table 4 Actuarially correct compensation for a one-year retirement age increase 35

Table 5 Partial privatisation of a pre-funded Defined Benefit system 41

Table 6 Transition to NDC 45

\section{FIGURES}

Figure 1 A pre-funded DB system: fair contributions, retirement age 60

Figure 2 Pre-funded DB system: standard accrual rate reduced and retirement age increased

Figure 3 Partial privatisation of the pre-funded DB system: retirement age $63 \quad 42$

Figure 4 Transition to NDC 


\section{Introduction}

\subsection{The purpose of this paper}

The threat to the financial sustainability of the pension systems in most European countries and elsewhere has become a major concern. Briefly, the problem stems from the fact that the pension systems established in many countries after WWII are now about to mature and bring a full pension to most people covered, while at the same time the ratio of pensioners to contributors (ratio of population $60+$ to $20-59$ years old) in the EU-15 will increase from 40 percent to over 70 percent between 2005 and $2050 .^{1}$

Twenty years ago, it was still believed that in Western Europe the problem of adverse demographic development would be temporary, caused by the postWWII "baby boom" generation retiring. To date, however, the consensus projections suggest that the new level of the old age dependency ratio to be reached around 2040 will be permanent.

The two principal demographic factors causing this are: (1) the gradual decline in fertility - from 2.1 children per female in the early 1970 s to about 1.7 by the mid$1990 \mathrm{~s}$ - a level which according to official projections will remain ${ }^{2}$, and (2) the fact that longevity has increased considerably, and is expected to increase still further, by nearly five years, between 2000 and 2050. Increasing longevity represents a problem because the retirement age, rather than increasing correspondingly, has fallen. Net migration is projected to settle at a fixed proportion of population, somewhat alleviating the process of ageing.

It is now recognised that population ageing will have serious consequences for public finances and for economies as a whole, but knowledge about the current facts, not to mention reasoned strategies, is fairly low (see Boeri, Börsch-Supan and Tabellini 2001 and 2002, covering four major EU countries).

This paper aims to help a reasoned discussion by tracking the problem to its two demographic roots, fertility and longevity, and by showing their consequences for pension systems and, most importantly, by presenting blueprints for exhaustive pension reforms. The chain of arguments is as follows:

1. If all successive generations have similar demographic characteristics, pcpulation age structure remains stable, which means that under a pure Pay-As-YouGo (PAYG) pension system they pay the same contributions and receive the

1 For population and pension expenditure projections for EU-15, see Economic Policy Committee (2001), "Budgetary challenges posed by ageing populations".

2 This refers to 'completed fertility' indicating the number of children of women who have passed fertile age. It is distinct from 'total fertility', which gives the ratio of births to women of fertile age. As the average age at which women give birth has recently increased, 'total fertility' has been lower than 'completed fertility'. 
same benefits as a percentage of wages; thus, under these conditions, continuing a PAYG is often perceived as a fair implicit contract across generations.

2. Under population ageing successive generations differ in terms of their demographic characteristics, thus, the same basic principle of intergenerational fairness requires adjustments to the pension system rules. For example, if the pension replacement rates and effective retirement age are maintained, the currently working generation should not only finance the pensions of the current retirees but also pay in contributions exceeding current expenditure, thereby prefinancing part of their own pensions. This leads, in general, to partial funding.

3. Partial funding can take place within the public sector, in which case public net debt is reduced, or lead to partial privatisation. Choosing between these two options will always have significant effects on public sector finances and should therefore be taken into account in adopting rules for public finances in general.

4. Instead of maintaining the current replacement rates the other extreme option is that these rates be decreased so that the current contribution rates provide the required financing. To arrive at this outcome in the long run, one solution is a transition to a Notional Defined Contribution (NDC) system, possibly accompanied by the introduction of a fully funded second pillar to prevent excessive reduction in the replacement rate.

5. In all options, an increase in the effective retirement age helps to contain the increase in pension expenditure and to prevent a drastic decline in pension levels.

From these elements we arrive at two basic blueprints for a pension reform, a transition either to a pre-funded and possibly partially privatised Defined Benefit (DB) system, or to a NDC system with a second pillar. In both reforms the level and/or the ratio between contributions and entitlements change. Also, as a rule, partial funding takes place within either a public or private pillar.

We confine the treatment to mandatory pension systems although for most results it makes no difference whether the system, or some part of it, is mandatory by law or quasi-mandatory under a collective agreement. Also, in the extreme cases where pension entitlements are drastically reduced to comply with the current contribution rate, and partial funding is therefore not required, private voluntary saving is expected to increase, thus building up private funds.

In designing the reform options financial sustainability is always required, defined most generally through its opposite: any system in which the debt ratio increases without limit is unsustainable, and hence breaks down sooner or later; thus, sustainability allows accumulation of debt (or assets), but it is required that the debt (or asset holdings) converges to some constant share of a scale of the economy.

The requirement of financial sustainability allows for a wide range of options, a pure DB PAYG system being one such by definition: contributions are ad- 
justed to cover the given expenditure at each point in time. However, an infinite number of other time paths for revenue may also cover the given expenditure over time, thus guaranteeing financial sustainability. Recognising this, we focus on a second criterion, intergenerational fairness, and arrive at a more limited number of reform options. This criterion looks into actuarial fairness, specifically across successive generations. We cover both $\mathrm{DB}$ and DC systems, and note the degree of funding in each option. ${ }^{3}$

\section{Outline}

In Chapter 2 we introduce a simple 3-period model to analyse a transition from one stable age structure to another after a decline in fertility and increase in longevity. The emphasis is on finding pension system rules which deliver intergenerational fairness not only under a stable age structure but also throughout the transition process, which is called population ageing. The simple 3-period model gives a number of important results, but as its structure is simplistic, it is not able to cope with all the important aspects of dynamic adjustment. Therefore, a yearly actuarial model is used in Chapter 3 to present simulations for reforming DB pension systems, and in Chapter 4 to analyse and illustrate the transition to an NDC pension system. The main implications are outlined in Chapter 5, and Chapter 6 concludes with a discussion of the main thrust of this paper.

\subsection{Agnosticism about arguments for funding in previous literature}

In this paper, the reasoning for partial funding is valid on its own, but as the issue of maintaining the pure PAYG systems or moving to (full or partial) funding and privatisation has been extensively debated by competing schools, the other main arguments are briefly reviewed below, though no position is taken on the issues debated. ${ }^{4}$

\section{Rate of return in alternative pension arrangements}

Most arguments in previous literature, first, in favour of introducing a PAYG system, and later, about a transition back from a pure PAYG system to funding and

3 Thus, we cover the three dimensions specified by Lindbeck (2001) and Lindbeck and Persson (2003): (1) provision of Defined Benefits (DB) or requiring Defined Contributions (DC) (2) degree of funding and (3) degree of actuarial fairness.

4 For more extensive reviews see Lindbeck and Persson (2003), Feldstein and Liebman (2002), Oksanen (2001a), Orszag and Stiglitz (2001), Sinn (2000), Disney (2000), Holzmann (1999), UN Economic Commission of Europe (1999), Diamond (1996) and the World Bank (1994). 
privatisation of pension financing, rest on the rate of return on contributions paid in each system

Samuelson's seminal paper of 1958 first stated the simple fact that, in a PAYG pension system in a steadily growing economy, the rate of return to pension contributions is equal to the rate of growth. He inferred that such a system improves welfare, contrasting it with an economy having no effective store of value, where the storing of real goods by workers for their retirement would yield a negative rate of return (which they would have to accept if there was no better alternative). We should note, however, that in the very same paper he also introduced a case where the existence of money solves the problem: with a zero nominal rate of return, workers can accumulate savings and use them during retirement. Assuming that the nominal stock of money is constant, he further inferred that the real rate of return on money balances is equal to the rate of growth of the economy, thus providing this real rate of return as savings for pensions. Thus, Samuelson (1958) introduced the basic elements of both a PAYG public pension system and a fully funded system (which could be either voluntary or mandatory by law). Under his highly theoretical (and counterfactual) cases, both systems produce the same welfare.

Aaron (1966) extended Samuelson's analysis to a modern economy where assets bearing a positive rate of return are available. He correctly derived the result that if the rate of growth of the economy (stemming from the rate of growth of population and wages) is higher than the rate of interest, then "the introduction of some social insurance pensions on a pay-as-you-go basis will improve the welfare position of each person", as compared to a reserve system. Aaron may have been partly right in considering that his result was relevant in the post-WWII growing economies, but later research led economists to understand that in a dynamically efficient economy, the rate of interest, in the long run, is equal to or higher than the rate of growth (this theorem of neoclassical growth theory is attributed to Cass 1965). In this light the steady state described by Aaron is a situation with an excessively large capital stock, which allows the economy to be adjusted to another steady state with higher consumption.

In more recent literature the question has shifted back to asking whether there is a case for shifting from pure PAYG systems to funding and privatisation of pension financing. The assertion of the neoclassical growth theory that the rate of return in a funded system (the rate of interest in the financial market), is normally higher than the rate of growth of the wage bill, led many authors to conclude that the funded system is more efficient. Therefore, a shift to funding would eventually yield additional returns which could at least partly compensate for the extra burden suffered by a generation which will have to save for its own pension and also honour the rights already accrued in the PAYG system. 
According to the opposing school, this reasoning is flawed, the counter-argument being that a shift to funding does not give a net welfare gain. This was clearly formulated by Breyer (1989, also 2001): a consistent analysis requires that the returns to funds and the discount rate to compare income streams at different points in time have to be the same, so that a shift to funding does not increase total welfare, but rather distributes it differently across generations.

The same broad conclusion was neatly derived by Sinn (2000): the difference between the market interest rate and the internal rate of return in the PAYG system does not indicate any inefficiency in the latter. Rather, this difference is the implicit interest paid by current and future generations on the implicit pension debt accumulated while some past generations received benefits without having (fully) contributed to anybody's pensions themselves. Under certain assumptions, continuation of the PAYG system is a fair arrangement to distribute this past burden between the current and all future generations.

A recent reaction and clarification from the proponents of funding is presented by Feldstein and Liebman (2002, 2297-2298): as our economies are still growing, it is proven that the marginal product of capital exceeds the social discount rate of future consumption. Thus, increased national saving, induced by a shift to funding of pensions, increases total welfare. It is therefore socially optimal to take this gain and share it between current and future generations.

Again, the response from those sceptical towards funding is that the additional saving could be achieved in many other ways, and that there is no convincing reason why the pension system should be used for this more general purpose. Feldstein and Liebman (2002) admit this, but maintain their view that it is advisable to reform the pension system to achieve this positive effect, regardless of the possibility that some other means could, in principle, lead to similar results.

A parallel chain of arguments and counter-arguments can be followed to examine the question of whether privatisation of pension fund management increases welfare by inducing a reallocation of capital towards investments with a higher return. The first argument is that in the long run, equity investment has a higher return than bonds, and that the privately managed pension funds may take advantage of this difference. The counter-arguments to this are again two-fold: (1) if it is assumed that markets are efficient, then risk-adjusted returns are equal and there is no gain from pension funding, or (2) if it is assumed that the markets are not efficient, there are many ways to change the allocation of capital, including government borrowing from the market and investing in risky assets. There is no compelling reason why the pension system should be used for this purpose (e.g. Orszag and Stiglitz 2001).

Thus, a transition to pension funding cannot be fully conclusively argued for on the basis of differences in rates of return or interest rates alone. Political econ- 
omy arguments referring to the political suitability of pension funding, as compared to other means, for acquiring welfare gains must also be explored. To assess this, the initial institutional structure must be looked at and the prospects of finding the political will to make the required - in most cases major changes to the pension system must be evaluated.

Here, we do not take a position on this controversy. As we build our argument on fairness of redistribution between successive generations, we can make a simple assumption of a uniform interest rate. However, our framework below is general in that it will also allow for simulations with differences in rates of return between alternative investments, thus making it possible to also illustrate the viewpoint of those who place greater emphasis on this aspect.

\section{Labour Market Distortion}

Another argument in favour of moving to funding and privatisation is based on the elimination of distortion in the labour market caused by the contributions paid to the public pension system, perceived as a tax on wages, while the contributions to a fund with individual accounts, even if mandatory, are supposed to be perceived by employees as saving for their future pensions. For this reason, it is argued that a transition to funding improves welfare by eliminating wasteful labour market distortion. This argument certainly bears some weight but gives a grossly exaggerated picture in favour of funding. Lindbeck and Persson (2003), for example, note this and argue that the degree of funding and actuarial fairness are two separate dimensions which can be combined in many different ways, and that actuarial fairness can also be strengthened in PAYG systems without introducing funding. A transition to an NDC system is a case in point. Fenge, Uebelmesser and Werding (2002) also give a refined analysis of the possible labour market distortion.

Again, as our argument for partial funding is not based on alleviation of labour market distortion, this channel is omitted from our formal modelling, but yet again, this does not imply any contradiction, but rather, under normal circumstances the two sets of arguments reinforce each other.

\section{Introducing fairness across generations under population ageing}

\subsection{An elementary analysis leading to partial funding and/or replacement rate reduction}

We assume a simplest possible earnings-related public pension system, where a pension as a percentage of wages is accrued by working and pensions are in- 
dexed to the wage rate. Labour is assumed to be uniform and the wage rate refers to wages after pension contribution payments. ${ }^{5}$

If the age structure of the population is stable, i.e. the number of pensioners as a percentage of workers is constant, all generations pay the same contribution rate and receive a pension which is the same percentage of the prevailing wage rate. Note that, for this, the population need not be stationary, but it is sufficient that its growth or decline is steady. The apparent equal treatment of all generations under these conditions has probably led those who favour preserving a PAYG system to regard it as a fair arrangement.

Here we show that following this same principle of fairness leads to partial funding under population ageing caused by a decline in fertility and/or increase in longevity. We should recognise that, in technical terms, ageing causes a transition of the pension system from one (hypothetical) steady state to another, not to be confused with a steady change which continues forever, even though, it takes, for example, an average life span before the full effect of a change in fertility has fully materialised.

The projected increase in the old age dependency ratio in the EU-15 until 2040 and the levelling-off which will follow should be understood as a transition determined by the permanent decline in fertility and the five-year increase in longevity until 2050.

As simple as possible a 3-period model is used to analyse what happens to pensions under an ageing population and how the rules should be designed to cope with the transition.

The population is composed of children $(E)$, workers $(L)$ and retirees $(R)$. Each of these phases of an individual's life is, for the purpose of managing the mathematics, set to be of equal length, which is set as the unit period:

$$
E_{t}=L_{t+1}=R_{t+2} \text {. }
$$

To keep a rough correspondence with real life, the unit period is best considered to last 30 years: this is currently the average childbearing age of women, and also, by chance, roughly the difference between the average age of a pensioner (70) and that of a worker (40).

Parameter $f$ expresses the number of children per worker (population then steadily decreases at a rate of $1-f$ :

5 The analysis below does not require any specific assumption about the wage rate growth, but we may note that, firstly, under population ageing, it may in most scenarios have to increase at a slower pace than labour productivity to leave room for the increasing pension contributions; secondly, as long as labour productivity and wages move together due to any exogenous factors, indexation of pensions to wages distributes the productivity gains evenly between workers and pensioners. 


$$
E_{t}=f_{t} L_{t} .
$$

The assumed pension system delivers pensions accrued at a specified rate of the wage by working and paying pension contributions. Pensions in payment are indexed to the wage rate. Taking the wage rate as the unit of account simplifies notation and allows for any movements of the wage rate, so that the results are solely driven by demographic dynamics, the rules of the pension system and the interest rate.

Pension as a percentage of the wage is

$$
p_{t}=\sigma_{t} \pi_{t-1}
$$

where $\pi_{t-1}$ is the accrual rate valid in period $t-1$ determining the pension to be received by the worker in the next period when retired, and $\sigma_{t}$ is a scale factor which, firstly, takes into account that in the formal analysis we artificially assume that the period at work and in retirement are of equal length. For example, if in reality the former is 40 years and the latter 18 , then $\sigma_{t}$ is 0.45 (= 18/40). Secondly, an increase in longevity, assuming a constant retirement age, can be introduced by assuming an increase in $\sigma_{t}$ : if people work for 40 years and longevity increases by five years, then $\sigma_{t}$ increases to $0.575(=23 / 40)$.

The contribution rate in each period $t$ is $c_{t}$. To construct a case which is more general than a pure PAYG system, we allow that the system owns financial reserves amounting to $q_{t}$ as a percentage of the wage bill. The rate of return on all assets, also measured in wage units, is assumed to be uniform and at least equal to the rate of growth of the wage bill. The interest factor is noted as $\rho_{t}$, i.e. $\rho_{t}-1$ is the rate of interest.

Period 0 is assumed to represent a steady state, i.e. fertility $f_{0}$ is assumed to have prevailed also in the past. The budget balance equation for period 0 reads as

$$
c_{0} L_{0}+\left(\rho_{-1}-1\right) q_{-1} L_{-1}=p_{0} R_{0}+q_{0} L_{0}-q_{-1} L_{-1} .
$$

Noting that in steady state $c, p, \rho$ and $q$ are constant, with subscript 0 , which stands for the old steady state values, and substituting from (1) and (2), we obtain

$$
c_{0}=\frac{p_{0}}{f_{0}}-\left(\frac{\rho_{0}}{f_{0}}-1\right) q_{0} .
$$

To derive results for population ageing, we assume that fertility declines in period 1 to $f_{n}$ and then stays at this new level. Subscript $n$ stands for the new value of the parameter after the change. Period 1 starts a transition, and period 2 is also transitional as the number of retirees is still determined by the previous fertility level. Period 3 is the first period of the new steady state, where the population declines at the new rate of $\left(1-f_{n}\right)$. 
If we first assume that pension accrual rate is maintained, we note that pension expenditure is the same as it was before the decline in fertility, not only in period 1 but also in period 2: However, in period 2, when the first generation of adults with the declined fertility have retired, the wage bill is lower as the number of workers is smaller. Therefore, if there has been no adjustment to the pension system, the contribution rate has to be increased to a new level, which will then be required in all subsequent periods.

The question of fairness arises. Why should the generation of workers in period 1 which initiated the decline in fertility escape the increase in the pension contribution rate to be encountered by all future generations? According to the principle that all generations with the same characteristics should be treated equally, the answer is that it should not, and that the regime should be changed. Several reform options exist.

\section{Partial funding}

In the first option, pension rights are maintained. This leads to higher expenditüre, requiring higher contributions. Fairness means that the first generation with lower fertility should pay the same percentage of wages in pension contributions as any succeeding generation. Thus, in period 1 , revenue should exceed expenditure, thereby creating a fund. Thanks to the proceeds from the fund, the contributions paid by all future generations are lower than in a pure PAYG system. This principle, leading to a permanent fund which covers part of the future pensions, was first outlined by Sinn (2000) and further developed by Oksanen (2001a, 2001b and 2002).

We also include in the analysis an increase in longevity, assuming a constant retirement age, due to which the ratio of the time in retirement to time at work increases from period 1 to 2 to a new value $\sigma_{n}$, leading to a new value $p_{n}$, which then remains constant. For fairness, this increase needs to be anticipated already in setting the contribution rate in period 1 , so that the workers in period 1 pay into the system according to their own future longevity.

The new contribution rate can be derived from the budget balance equations for period 1 and from period 2 onwards, which read as follows:

$$
\begin{aligned}
& c_{n} L_{1}+\left(\rho_{0}-1\right) q_{0} L_{0}=p_{0} R_{1}+q_{n} L_{1}-q_{0} L_{0}, \text { and } \\
& c_{n} L_{t}+\left(\rho_{0}-1\right) q_{n} L_{t-1}=p_{n} R_{t}+q_{n}\left(L_{t}-L_{t-1}\right) .
\end{aligned}
$$

From these equations we obtain for the new contribution rate 


$$
c_{n}^{*}=\frac{1}{\rho_{n}} p_{n}+\frac{\rho_{n}-f_{n}}{f_{0} \rho_{n}} p_{0}-\frac{\left(\rho_{n}-f_{n}\right) \rho_{0}}{f_{0} \rho_{n}} q_{0}
$$

and for the new degree of funding

$$
q_{n}^{*}=\frac{1}{\rho_{n}} p_{n}-\frac{f_{n}}{f_{0} \rho_{n}} p_{0}+\frac{f_{n} \rho_{0}}{f_{0} \rho_{n}} q_{0} .
$$

While these two expressions give the result for the general case where nothing particular is assumed about the interest rate, it is conventionally assumed, backed by elementary growth theory, that the interest rate follows the growth rate of the economy exceeding it by a constant margin. Following on from our assumption that the level of production is determined by the size of the labour force, which is again determined by fertility in the previous period, for the new interest factor, which is valid again from period 2 onwards, we get:

$$
\rho_{n}=\frac{\rho_{0} f_{n}}{f_{0}} .
$$

Solving for the new contribution rate and the change in the degree of funding gives in this case

$$
\begin{gathered}
c_{n}^{* *}=\frac{f_{0}}{f_{n} \rho_{0}} p_{n}+\frac{\rho_{0}-f_{0}}{f_{0} \rho_{0}} p_{0}-\left(\frac{\rho_{0}}{f_{0}}-1\right) q_{0} \text { and } \\
q_{n}^{* *}-q_{0}=\frac{f_{0}}{\rho_{0} f_{n}} p_{n}-\frac{1}{\rho_{0}} p_{0} .
\end{gathered}
$$

The latter equation is written in such a way as to show that under this assumption on the interest rate the change in the degree of funding does not depend on its initial level.

\section{Reduction of replacement rate}

Another option is that the contribution rate is kept constant, but the replacement rate reduced from period 2 onwards, which means that the decreased accrual rate is in force already in period 1 for the first generation of workers with the lower fertility and increasing longevity.

In the general case, the new value for pension benefit can be derived by substituting $c_{0}$ from equations (5) to (8). Omitting this for brevity, only the case where the interest rate is assumed to follow (10) is presented, giving a simple result 


$$
p^{* * *}=\frac{f_{n}}{f_{0}} p_{0} .
$$

Substitution from (13) to (12) shows that in this case the degree of funding does not change.

\section{Illustrations with simple numbers}

Table 1 illustrates the results with examples. Fertility is initially 1 and then declines in period 1 to 0.8 . These figures roughly correspond to the 20 percent decline in the EU on average over a generation: the female generation born in the early 1940s, giving birth on average in the early 1970s, had a reproduction level of 2.1 , while the most recent figure is 1.7 .

Initially, the ratio of time in retirement to time at work, parameter $\sigma_{t}$, is assumed to be 0.45 (based on 18 and 40 years respectively). This, coupled with an assumption that the replacement rate proper is 60 percent (1.5 percent eamed in each year), gives $p_{0}=0.27$. For workers in period 1 and all subsequent generations longevity is assumed to increase by five years. If replacement rate and retirement age are kept constant, $\sigma_{t}$ increases to $0.575(=23 / 40)$, and $p_{t}$ to 34.5 percent. It is assumed, for simplicity, and also to highlight the challenges faced by the public pension systems in most European welfare states, that initially no reserves exist, thus $q_{0}=0$. From these numbers it follows that in the initial steady state the contribution rate is 27 percent.

In the initial steady state the rate of interest is assumed to be 50 percent, which corresponds to 1.36 percent per annum over the 30 years (i.e. from one generation to the next). Then, we make the conventional assumption that the interest rate is at this fixed margin above the growth rate of the wage bill, following equation (10) above.

In Table 1, periods 0-3 describe the transition from the old steady state to the new. Period 4 figures are displayed only to convince the reader that period 3 represents the new steady state as all relative numbers remain unchanged from period 3 .

For all scenarios 1-3, we display the Implicit Pension Debt (IPD) which, for each period, is defined as the pension expenditure in the next period, discounted at the prevailing rate of interest (row 5), internal rate of return for each generation defined as the rate earned on contributions in terms of pension benefit, and implicit tax inherent in the contribution payments under unfunded or only partially funded public pension schemes (see Fenge and Werding $2003 \mathrm{a}$ and $2003 \mathrm{~b}$ for further discussion of these concepts). The latter is best understood, particularly in the context of present illustrations, as the excess of 
the contribution rate over that under a fully funded system offering the same level of pension benefits, shown in Scenarios $5 \mathrm{a}-\mathrm{b}$ in Table 2 (another expression: the implicit tax stems from the excess of the rate of interest in the financial market over the rate of change of the wage bill, levied on the IPD).

Scenario 1 displays the pure PAYG system with no adjustment for period 1 . The new contribution rate required from period 2 onwards is 43.1 percent. In order to ascertain the relative importance of the two demographic factors we may calculate (using equation 11) that the decline in fertility alone would require a contribution rate of 33.8 percent $(=0.27 / 0.8)$, and the increase in longevity a rate of 34.5 percent $(0.27 * 23 / 18)$; thus they are almost equally important.

Scenario 2 illustrates the case for moving to partial funding with the replacement rate maintained, but contributions increased from period 1 onwards to meet the requirement of fairness explained above. Expenditure is the same as in Scenario 1 . The new contribution rate derived from equation (11) is 37.75 percent. The resulting permanent fund is 323 percent, expressed as a percentage of the annual wage bill (row 14).

Scenario 3 illustrates a case for maintaining the initial contribution rate by reducing the replacement rate so that the system is balanced. This requires that the workers in period 1 receive reduced benefits, i.e. their accrual rate is reduced. The numbers above imply that the replacement rate proper should decrease from 60 to 37.6 percent (this holds irrespective of the assumption on the interest rate as we assumed no initial reserves). The link to further issues is that putting the necessary adjustment on the reduction of the replacement rate only may trigger an introduction of a mandatory supplementary pillar and/or increase in voluntary pension saving to top up pensioners' income. Thus, partial funding would take a form other than that in Scenario 2.

In Scenario 1 IPD increases from the initial 540 to 863 percent of the annual wage bill, indicating the increase in pension burden. In Scenario 2, IPD minus the fund as a percentage of the wage bill, 540 percent, is the same as IPD in the initial steady state, indicating that all generations leave the same burden to their descendants. The permanent degree of funding, defined as fund assets as a percentage of IPD, is 37 percent $(=323 / 863)$. In Scenario 3, IDP naturally does not change, indicating fairness. 
Table 1

\section{Scenarios for pension reforms under population ageing}

\begin{tabular}{|c|c|c|c|c|c|}
\hline Period & 0 & 1 & 2 & 3 & 4 \\
\hline 1 E children & 100 & 80 & 64 & 51 & 41 \\
\hline $2 \mathrm{~L}$ labour $=$ wage bill $(w b)$ & 100 & 100 & 80 & 64 & 51 \\
\hline $3 \mathrm{R}$ retired & 100 & 100 & 100 & 80 & 64 \\
\hline 4 Change in $w b, \%$ & 0 & 0 & -20 & -20 & -20 \\
\hline 5 Interest rate, $\%$ & 50 & 50 & 20 & 20 & 20 \\
\hline
\end{tabular}

Scenario 1. Pure PAYG, replacement rate proper constant at $60 \% ; p_{n}=0.345$

$\begin{array}{lrrrrr}\text { 6 Pension expenditure } & 27.0 & 27.0 & 34.5 & 27.6 & 22.1 \\ 7 \text { Contr. rate=pens.exp., \% of } w b & 27.0 & 27.0 & 43.1 & 43.1 & 43.1 \\ 8 \text { IPD, \% of } w b & 18.0 & 28.8 & 28.8 & 28.8 & 28.8 \\ 9 \text { 30*IPD, \% of } w b & 540 & 863 & 863 & 863 & 863 \\ 10 \text { Internal rate of return, \%* } & 0 & 0 & 28 & -20 & -20 \\ 11 \text { Implicit tax, \% of wage } & 9.0 & -1.8 & 14.4 & 14.4 & 14.4\end{array}$

Scenario 2. Const. repl. rate; contr. rate $37.75 \%$ from per. $1 ; p_{n}=0.345, c_{n}$ from eq.(11)

$\begin{array}{lrrrrr}12 \text { Contr. rate, \% } & 27.00 & 37.75 & 37.75 & 37.75 & 37.75 \\ 13 \text { Fund, \% of } w b & 0.0 & 10.8 & 10.8 & 10.8 & 10.8 \\ 1430 * \text { Fund, \% of } w b & 0 & 323 & 323 & 323 & 323 \\ 1530 * \text { IPD, \% of } w b & 540 & 863 & 863 & 863 & 863 \\ 1630 * \text { IPD-Fund, \% of } w b & 540 & 540 & 540 & 540 & 540 \\ 17 \text { Internal rate of return, \%* } & 0.0 & 0.0 & -8.6 & -8.6 & -8.6 \\ 18 \text { Implicit tax, \% of wage } & 9 & 9 & 9 & 9 & 9\end{array}$

Scenario 3. Pure PAYG, contr. rate const. at $27 \%$, repl. rate $37.6 \%$ from per. $2 ; p_{n}=0.216$

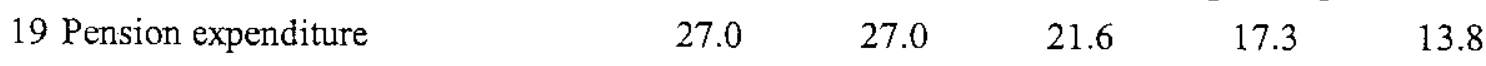

$2030 *$ IPD, \% of $w b \quad 540 \quad 540 \quad 540 \quad 540 \quad 540$

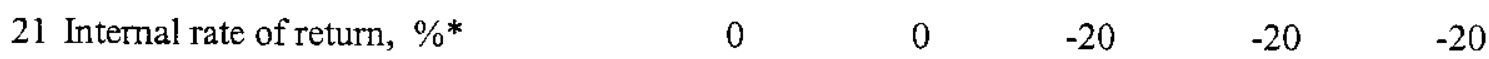

22 Implicit tax, \% of wage $\quad 9 \quad 9 \quad 9 \quad 9 \quad 9$

Scenario 4. Acquired rights respected \& no new rights: new contr. rate $9 \% ; p_{n}=0$

23 Contr. rate, $\%$

24 Pension expenditure

27

$27 \quad 27$

$2530 *$ Fund, $\%$ of $w b$

$0 \quad-540$

9

$9 \quad 9$

9

26 Internal rate of return, \%*

0

27 . 0

$0 \quad 0$

0

27 Implicit tax, \% of wage

9

$0 \quad-100 \quad-100$

* for the generation of retirees in each period

Assumptions: Initial fertility preserves a constant population: $f_{0}=1$. - Initially 40 years at work, 18 in retirement: $\sigma_{0}=0.45=18 / 40$ ) - Initial replacement rate proper $60 \%$, or $\pi_{0}=0.6$, requiring, according to eq. (5), contribution rate $\left(c_{0}\right)$ of $27 \%$. Initially no reserves: $q_{0}=0$. - In period 1 fertility declines by $20 \%: f_{n}=0.8$. - Longevity increases: from period 2 onwards 23 years in retirement: $\sigma_{n}=0.575(=23 / 40)$. - Interest rate $50 \%$ in period 0 ; declines with the wage bill: $\rho_{0}$ $=1.5, \rho_{n}=1.2$ from eq. (10). - Unit of account: wage rate. 
Table 2

A fully funded pension system under population ageing

$\begin{array}{llllll}\text { Period } & 0 & 1 & 2 & 3 & 4\end{array}$

Scenario 5a. Full DC fund, contr. fixed at $18 \%$, repl. rate falls to $37.6 \% ; p_{n}=0.216$.

$\begin{array}{lrrrrr}28 \text { Cap. value of pens., \% of } w b & 27.0 & 27.0 & 21.6 & 21.6 & 21.6 \\ 2930 * \text { Fund, \% of } w b & 540 & 540 & 540 & 540 & 540\end{array}$

Scenario 5b. Full DC fund, target repI. rate $60 \%$; new contr. rate $28.75 \%: p_{n}=0.345$.

$\begin{array}{lrrrrr}30 \text { Cap. value of pens., \% of } w b & 27.0 & 27.0 & 34.5 & 34.5 & 34.5 \\ 3130 * \text { Fund, \% of } w b & 540 & 863 & 863 & 863 & 863\end{array}$

* for the generation of retirees in each period

Assumptions: Initial fertility preserves a constant population: $f_{0}=1$. - Initially 40 years at work, 18 in retirement: $\sigma_{0}=0.45=18 / 40$ ) - Initial replacement rate proper $60 \%$, requiring $18 \%$ contribution rate. - In period 1 fertility declines by $20 \%: f_{n}=0.8$. - Longevity increases: from period 2 onwards 23 years in retirement: $\sigma_{n}=0.575(=23 / 40)$. - Interest rate $50 \%$ in period 0 ; declines with the wage bill: $\rho_{0}=1.5, \rho_{n}=1.2$ from eq. (10). - Unit of account: wage rate.

In pure PAYG systems under a steady state the internal rate of return is equal to the increase in the wage bill, thus, in Scenarios 1 and 3, measured in wage units, it declines from 0 to -20 percent when the system moves from the initial steady state to the new in period 3. This reiterates the old simple result by Samuelson (1958). The present analysis also tackles the more interesting and relevant issue of what happens under population ageing: in Scenario 1, period 1 workers receive, as retirees in period 2, an undue, exceptionally high rate of return of 28 percent. If this unfairness is eliminated, as in Scenario 3, by reducing the benefits already in period 2, the rate of return immediately declines to its permanent level of -20 percent. In Scenario 2 benefits are fixed and faimess is implemented by increasing contributions already in period 1 , leading to partial funding. The result is a rate of return of -8.6 percent for all generations after the demographic change. This figure is a weighted average of the -20 percent under pure PAYG and the +20 percent return on the financial assets acquired by the newly established fund.

The figures for implicit tax (lines 11, 18 and 22) complete the picture. As the internal rate of return, implicit tax is also constant under a steady state, initially 9 percent of wages, and may change under population ageing. In Scenario 1, the pure PAYG with constant benefits, the workers in period 1 gain considerably: their implicit tax is negative. This explains why all subsequent generations have to pay a higher implicit tax of 14.4 percent.

Scenarios 2 and 3 are designed to be fair for all generations from period 0 onwards. This is confirmed by implicit tax staying constant at 9 percent. Thus, the burden 
stemming from benefits given to generations before period 0 is fairly shared, taking into account the changed demographic characteristics of the subsequent generations.

Any combination of Scenarios 2 and 3 would meet the criterion of fairness, keeping IDP-Fund and the implicit tax as percent of the wage bill constant. Thus, it is a matter of collective choice as to how much the contribution rate should be increased and the replacement rate reduced. Equation (11) gives any combination which implements faimess, under the particular assumption on the interest rate. As an example (not shown in the table), the replacement rate could be reduced to 50 percent (by reducing the yearly accrual rate from 1.5 percent a year to 1.25 percent), as is roughly the case in several current projections and reform proposals. In this case, the new fair contribution rate is 33 percent, and the resulting permanent fund 179 percent of the wage bill, i.e. the increase in the contribution rate and the fund are a little more than half of those in Scenario 2.

However, reforms implementing fairness are not restricted to combinations of Scenarios 2 and 3. Accumulation of new rights can be reduced even further than in Scenario 3, for example if the public pension system is drastically cut back and replaced by a private system. Scenario 4 displays an extreme case: the period 1 workers decide to respect the acquired rights of period 1 retirees, being ready to share the burden with all subsequent generations, but completely abolish public pensions for themselves. The outcome is that period 1 workers should pay in 9 percent as contributions, and as expenditure is still 27 percent, the system borrows the missing 18 percent of the wage bill. All future generations then pay the same 9 percent contribution for servicing the debt so that the debt/wage bill ratio remains constant. Thus, IPD becomes explicit debt, and the implicit tax becomes explicit as it is paid, without any pension benefits, by all workers from period 1 onwards. Again, any combination of this extreme case and Scenario 2 would respect the principle of fairness across generations.

\subsection{A transition to a Notional Defined Contribution (NDC) system}

The numbers in Scenario 3 can also be interpreted as a prototype of a Notional Defined Contribution (NDC) system. A transition to NDC from a public DB system means that contributions are fixed, registered on notional individual accounts which receive an administratively fixed rate of interest, and the capitalised value at retirement is transformed into an annuity paid out as a pension. The proponents of NDC reforms underline that moving from DB to NDC delivers, under certain conditions, equality of pension expenditure and contribution revenue in the long run.

Financial stability requires the contribution rate to be fixed, the notional rate of interest to be set as the rate of growth of the wage bill ( $w b$, which is the contri- 
bution base), and projections of life expectancy at retirement to be continuously updated and correspond to the real outcomes. In addition, we make the conventional assumption that in each period, interest is paid on the balance of the account in the previous period, i.e. the notional interest rate is set equal to the change in wage bill in the period when the contributor has retired, i.e. pension benefits in any period $t$ are:

$$
p_{t}=c_{-1}\left(1+w b_{t}\right)
$$

Writing for expenditure and substituting from (1) and (14), and noting that the contribution rate is constant $c_{c}$, i.e. $c_{t-1}=c_{t}=c_{c}$, gives

$$
p_{t} R_{t}=c_{-1} \frac{L_{t}}{L_{-1}} L_{-1}=c_{c} L_{t}
$$

which equals revenue in period $t$, i.e. the system is in balance irrespective of changes in the number of workers (stemming here from changes in fertility).

Scenario 3 illustrates this simple NDC model, whether assumed to have been operating under NDC in all past periods or to be transformed from a DB system to NDC in period 1 . The capital value of the pension $p_{t}$ reduces in period 2 to 21.6 percent, reflecting the decrease in the rate of change in the wage bill in period 2. This reduction and the NDC rule that the annuity is also reduced due to the increase in longevity lead to a reduction in total pension expenditure to the level of total contribution revenue. ${ }^{6}$

In this elementary case of an NDC system with the prescribed notional interest rate, it is noteworthy that financial stability is fulfilled not only in the steady state but also over the transition period. This is an advantage as compared to a DB system, where an early adjustment of the accrual rate is needed. It has to be recognised also, however, that the 3-period model above is simplistic in the sense that each generation fully feels the consequences of its own fertility (which determines the change in the wage bill in the period of their retirement, which in turn determines their pensions). This is not the case in real life as age cohorts overlap and interest on the pension account is accrued on a yearly basis throughout the participant's working life. Therefore, quite correctly, some previous authors (e.g. Valdes-Prieto, 2000) empha-

6 To demonstrate the equivalence of a DB system where the replacement rate is adjusted for financial balance and the NDC system with the above rule, note that in the former the budget equation reads as $p_{t} R_{t}=c_{c} L_{t}$, which gives for $p_{t}=c_{c} L_{t} / L_{-1}=c_{c}\left(1+w b_{t}\right)$, i.e. equivalent to equation (14). 
sise that under plausible assumptions an NCD system as prescribed above is not automatically fully balanced.

This should not, however, lead to the conclusion that an NDC system is no better than a traditional DB plan. A transition to an NDC system, designed along the simple lines above, can be seen to cover the bulk of the adjustment required for financial sustainability, and an additional adjustment directly or indirectly reflecting the changes in fertility or any other factors could be designed to take care of the rest. In Chapter 4 we shall analyse some of these aspects, while confirming the positive overall assessment regarding welldesigned NDC systems.

\subsection{A fully funded defined contribution (FF DC) system}

A brief reference to scenarios for a Fully Funded Defined Contribution (FF DC) system, under otherwise identical assumptions as above, are useful to highlight the differences and similarities across a wide range of pension systems. They are also presented to provide the benchmark for calculating the implicit tax rate in the unfunded or partially funded systems in Scenarios 1-3 in Table 1. As a FF DC system is relatively simple, no equations are written down; note, however, that this case could be described by the equations above by setting the initial fund equal to IPD.

In a FF DC system benefits are acquired by contributing to an individual account, invested by fund managers, with pension determined by the contributions, the proceeds of the fund and - normally - by buying an annuity at the moment of retirement. Assuming that initially the rate of return on assets is 50 percent, a contribution rate of 18 percent $(=0.27 / 1.5)$ delivers the same level of pension as in all cases in Table 1.

If population ageing does not affect the rate of interest, then, evidently, any level of contributions provides the same capital value of pension regardless of population ageing. Change in longevity, assuming a fixed retirement age, naturally has an impact on the ratio between contributions and pension annuity: if the time in retirement increases from 18 years to 23 , then the annuity declines from 60 percent to 47 percent $(=0.27 * 40 / 23)$.

However, the conventional assumption of the interest rate, equation (10), assumed to hold in Scenario 5a in Table 2, leads to the same decline in the replacement rate as in the PAYG with the fixed contribution rate. The capital value of the pension reduces to 21.6 percent, implying an annuity equal to the new replacement rate as in Scenario 3, 37.6 percent from period 2 onwards, thus fully affecting the pensions of the workers in period 1 who reduced the fertility rate. As 
the contributions remain constant, so does the fund as a percentage of the wage bill (540 percent). However, it delivers lower pensions as the rate of interest declines.

If the initial replacement rate proper, 60 percent, is targeted, as assumed in Scenario $5 \mathrm{~b}$, then the capital value of pension benefits needs to be increased to 34.5 percent $(0.27 * 23 / 18)$. To achieve this under the new interest rate of 20 percent, a contribution rate of 28.75 percent is required. The fund as a percentage of the wage bill increases to the same number as IPD in Scenarios 1 and 2 ( 863 percent).

\subsection{Retirement age increase and actuarial fairness}

The simple model above, even though working and retirement years are simply compressed to one period each, can be used for some basic results for a retirement age increase by incorporating it through a change in parameter $\sigma_{\mathrm{t}}$.

If, in an ageing population, people do not want to either pay higher contributions or accept a lower replacement rate, then they have to work longer. The simple numbers above lead to the result that working 6.3 years longer is necessary, thus 46.3 years at work and 16.7 years at retirement is required.

We should first note that arriving at the initial replacement rate of 60 percent requires that the pension accrual rate per year be reduced from 1.5 to 1.3 percent $(=$ 60/46.3). Unfortunately, this would reduce the incentives to stay at work. Therefore, if increasing the retirement age is a public policy target, the pension accrual rate might need to be higher over the potential last years at work. If then the ultimate replacement rate is to be maintained at 60 percent, the accrual rate for prime age workers needs to be reduced even below 1.3 percent.

This reasoning shows that placing all the burden of adjustment on the retirement age is a complex issue, and may not be the most likely outcome of pension reforms. Therefore, below we combine a retirement age increase with the other two measures, partial funding and reduction of the replacement rate, using a yearly model to better capture the various dynamic features of the adjustment process.

\subsection{The thrust and limitations of the 3-period model}

Interpreting the results above and referring to previous literature, we should distinguish between two aspects of fairness. One is that in all cases above, pensions were assumed to be indexed to the wage rate. The other is that in an ageing population the ratio between contributions paid and benefits received must change from one generation to another. 
The first property is considered desirable by many, notably by Musgrave (1986), who named it 'fixed relative position'. This principle is reiterated by Esping-Andersen et al. (2002), and by Schokkaert and Van Parijs (2003). It simply means indexation of pensions to wages after pension contributions, as assumed above. As soon as gains from an increase in productivity show up in the wage rate, they are automatically shared between current workers and pensioners. However, Musgrave's rule is fair only if the ratio between pensioners and workers is constant. The thrust of our exercise with the simple 3-period model is to show that under population ageing fairness requires a fundamental adjustment to DB PAYG system rules.

Our analysis extends the important result by Sinn (2000), explained in Section 1.2 , about the 'introductory gains', which are the origin of the implicit debt in a PAYG system: under ageing, any generation which does not pay into the system the fair share corresponding to its demographic characteristics enjoys an unfair gain and leaves an increased burden to future generations.

The scenarios above offer a framework to generalise "introductory gains" to population ageing and to demonstrate how IPD, internal rate of return and implicit tax relate to each other. Initially, "introductory gains" had led to IPD of 540 percent, and as a consequence, in the pure PAYG system, the contribution rate is $9(=27-18)$ percentage points (p.p.) higher than in the corresponding FF DC. This difference is the implicit tax necessary to serve the IPD. Under the pure DB PAYG system in Scenario 1, the implicit tax increases in period 2 to 14.4 percent.

Implementing fairness in Scenarios 2-4, i.e. giving no undue gains to the workers in period 1, IDP-Fund as percent of the wage bill remains constant at 540 percent, and also the implicit tax remains at 9 percent. The internal rate of return changes in all cases, but reaches a very different level depending on the size of the public pension system in the new steady state. Thus, movements in the internal rate of return are not an adequate indicator of whether the adjustment to ageing is fairly done (yet, in our simple cases, fairness is demonstrated by period 1 workers receiving, as retirees in period 2 , the same rate of return as all succeeding generations).$^{7}$

7. Describing a pure PAYG as a "Ponzi game", as Disney (2000) does - a description that has found its way into the press (The Economist, Supplement, Pensions, 16 February, 2002) - is an exaggeration and analytically dubious. In a Ponzi game somebody cashes an abnormal return now as people send him money in the expectation that they themselves will get the same abnormal return from the next round of people. This arrangement is not sustainable and the system always collapses. In a prototype pure PAYG under a steady state, the internal rate of return is the increase in the wage bill, which is normaliy lower than the rate of interest. Under ageing, these rules lead to an increase in the contribution rate, but the new rate under the new steady state is again constant, and the internal rate of return is the new rate of change of the wage bill. Thus the problem is not intrinsic unsustainability of the system, as it is in any "Ponzi game", but rather, fairness with regard to the generation(s) which gain from the introduction of a pure DB PAYG system, and, as shown above, also later when the pension system has matured, with regard to any generation with new demographic characteristics. 
However, these neat results, especially concerning IDP-Fund and implicit tax as indicators of fairness, crucially depend on the particular assumption on the interest rate, i.e. that the interest rate is at a fixed margin above the growth rate of the wage bill. The other alternative for a basic assumption is a fixed rate of interest. The latter is typically argued on the grounds of a small open economy, meaning that the rate of interest is determined in the international financial markets regardless of population ageing at home.

Extending our discussion to this case is not a problem as the results of the analytical model, given by equations (8) and (9), allow any assumption of the interest rate. All results in Tables 1 and 2 could be reproduced assuming a fixed interest rate, but for brevity, only selected comments are made here.

Firstly, as with a fixed interest rate the premium over the rate of growth of the wage bill increases, the implicit tax also increases, from 9 percent to 12.6 percent in all cases corresponding to Scenarios 2-4. IDP may go in a different direction: for example in a case corresponding to Scenario 3, IDP falls for the simple reason that the discount factor is higher than in the case in Table 1 (though again remaining constant from period 1 onwards). Thus, neither of these two indicators, if used to analyse a process of ageing, correctly indicates whether intergenerational fairness is implemented. For example, if fixed interest rate is assumed and the implicit tax is projected to increase, it may not be clear as to whether (or to what extent) this increase stems from the increasing margin of the interest rate over the rate of growth or from the undue benefits extracted by the current generation of workers through an insufficiently reformed pension system (cf. Fenge and Werding 2003a and 2003b).

This leads to a methodological conclusion that projections for the pension reforms aiming at highlighting not only financial sustainability but also intergenerational fairness should first be based on the assumption that the interest rate falls with the rate of growth of the wage bill (or some other measure of economic growth). Fortunately, this pattern of interest rates is also supported by the fact that fertility has declined in most countries, leading to a decline in the rate of growth of the labour force, which, under fairly general assumptions, is understood to lead to declining interest rates (e.g. European Commission, 2002 , Ch. 4). Thus, interest rates can be assumed to fall even in a small country, while the channel of causality is not decisive for the scenarios above (as in many other practically oriented simulations).

In any case, the simple assumption that the interest rate follows the decline of the rate of growth of the wage bill, equation (10) above, leads to a number of neat analytical results. It is therefore a useful basis for basic scenarios, especially geared for judging intergenerational fairness of reform proposals, to be followed also in the rest of this paper. However, looking more carefully into 
the determination of the interest rate and its implications might be worthwhile for any further applications for policy design.

As for the generality of the analysis above, it should be noted that while we technically assume a once-and-for-all permanent change in fertility and longevity, it does not significantly hamper the application of the results: after having calculated the results for period 1, determining pensions in period 2, a change in the demographic factors occurring in period 2 can be introduced, allowing for a calculation of the new values for the pension system parameters for periods 2 and 3 , and so on.

Finally, we should note that in the analysis above peoples' lives are compressed to three periods and that at each point in time there is no overlap of workers born in different periods. These are artificial assumptions, which greatly simplify the analysis, without impeding the main thrust of it. However, for more realistic cases, notably for adjustment paths, we need to turn to a yearly actuarial model as developed in the following Chapters.

\section{Reforms to a DB system illustrated with an actuarial model}

Since, in real life, age cohorts overlap considerably, the dynamics of population ageing and pension reforms cannot be fully captured without a yearly actuarial model. In particular, it means that implementing complete fairness across the succeeding yearly cohorts requires specific contribution and/or replacement rates for each of them, as shown by Kifmann and Schindler (2001). We take another route and assume that at each moment in time the contribution rates are the same for everybody, as they normally are in the real world. This makes complete fairness across cohorts unachievable. However, a number of simulation exercises using a yearly actuarial model are presented to show how the principle of fairness can be striven for, even though the ideal solutions are beyond reach. We can also demonstrate that various optional reforms compare favourably with the continuation of a pure DB PAYG system.

\subsection{The actuarial model}

We insert into a yearly actuarial model stylised facts about demographic development and initial pension system parameters roughly resembling those of European welfare states. Then we introduce various pension reform options, and illustrate the emerging transition paths from one system to another.

In the model, successive yearly cohorts are followed through their lives. They start as children, work and give birth to the next generation, and then retire. The model covers only the pension system, leaving the economy outside the model unspecified. 
This has two major advantages: (1) the model remains relatively simple, and (2) the relevant variables, which are exogenous to the pension system, are transparently fixed by assumption. The key exogenous variables are the premium of the interest rate over the wage bill growth, real wage growth, and inflation.

As for the interest rate, we follow the simple and convenient assumption discussed in Chapter 2 that it moves with the wage bill. This greatly simplifies certain results, although the most important qualitative conclusions would hold also for more general cases. As for the real wage (reflecting change in labour productivity) and inflation, it is comforting that most results below will not depend on these variables as we additionally assume that pensions are indexed to wages (or to the wage bill). This can be considered to be a good approximation of reality in the long term, thus making most of our results applicable very generally. The model would allow for any other assumptions with regard to indexing rules and consequently to wage rate and inflation assumptions, but as illustrating such cases leads to a very rapid increase in possible combinations, it is left for further studies.

Most results are reported as a percentage of the wage bill (after pension contributions). A rough key to relate the figures to GDP is to multiply them by 0.4 as the EU-15 wage bill (without employers' social security contributions) was roughly 40 percent of GDP in 2000 . This approximation does not cover all workers, excluding, for example, the self-employed and those outside employment, but as we assume that initially pension expenditure is 27 percent of the wage bill, this simple key gives 11 percent of GDP, which corresponds to the EU-15 average in 2000 .

\subsection{Base case assumptions}

For the initial values, we assume, as in Chapter 2, that all people live 20 years as children, work for 40 years until the age of 60 , and enjoy retirement for 18 years. In a public DB pension system, each year, workers earn a pension right equal to 1.5 percent of their salary, so that working for 40 years gives a 60 percent replacement rate.

The growth rate of real wage is assumed to be 1.75 percent per annum (if pension contributions are partly paid by the employee, then the definition of the wage is 'the wage after pension contributions but before taxes'). Inflation is assumed at 1.5 percent p.a. Interest rate $(r)$ is assumed, in the base case, to be uniform at 1.5 p.p. above the rate of change of the wage bill $(w b)$. This order of magnitude is conventionally assumed in long-term analysis.

With these numbers the contribution rate is 27 percent and IPD 610 percent of the wage bill. 
We assume that fertility was constantly at 2.1 until 1980 , then declined to 1.7 in 1981 and remains at that level. The purpose of this simple assumption is to show clearly the consequences of one single change in fertility, and to design reforms to cope with the adverse effects (in reality, fertility has declined gradually; this could be analysed by the model as a series of successive changes). Secondly, we include in the analysis a gradual increase in longevity from 78 to 83 from 2000 to $2050 .{ }^{8}$

\subsection{Pre-funding a DB system with fixed replacement rate and retirement age}

We first assume that pension accrual rate and retirement age are maintained, and that the system is reformed in 2001 to comply with the faimess requirement by adjusting the contribution rate (as in Scenario 2 in Ch. 2). Now that we are working with a yearly model, the rule for gradual adjustment needs to be introduced. As stated above, at each point in time the pension contribution rate is set to be the same for everyone, as it normally is in a DB PAYG system. Therefore, as the group of workers includes both those with the previous level and those with the new level of fertility, and as their longevity varies, complete fairness for all cannot be delivered. However, we attempt to set a time path for the contribution rate during the transitional phase such that in each year, on average, the age-cohorts are fairly treated.

Figure 1 illustrates the results. Expenditure increases to 45 percent of the wage bill. The contribution rate is increased to 38.4 percent by 2020 , with an initial immediate jump in 2001, followed by a gradual increase. The details of the derivation of this path are given in Box 1 .

The surplus peaks at 15 percent of the wage bill in 2019, converges to 10.5 percent, and results in a permanent fund of 427 percent of the wage bill. The difference between IPD and the fund which, under pre-funding, is a measure of the burden to be carried over from one generation to the next, is 665 percent, i.e. slightly higher than

8 These two simple demographic assumptions produce an old age dependency ratio (OADR), defined as the ratio between population over 60 years of age to 20-59 years old, which roughly resembles the actual population projections for EU-15, though starting from a higher level. The real world projection then catches up as the big post-WWII 'baby boom' cohorts reach the age of 60 and over, so that the two data reach roughly the same level in 2050 . Thus, while we do not claim that our results represent real data, they give useful approximations - not forgetting that the real world situation is probably even more worrying. The initial stylised data used in this Chapter slightly differ from those in Chapter 2 as we use rounded figures, and move to a yearly model from the simple three-period setting above. However, the orders of magnitude for key results are the same. 
610 percent, which was the initial IPD with a stationary population. The degree of funding, i.e. the ratio between the fund and IPD, is 39 percent.

We may note that the resulting figures are very close to those in the corresponding, more simplistic, scenario in the previous chapter. For example, the contribution rates here and in Chapter 2 are 38.4 percent and 37.75 percent respectively, and the degree of funding is 39 percent and 37 percent.

The significant increases in contribution rates and extensive accumulation of funds in 30-60 years may seem unrealistic and unacceptable. While this may be the case, this scenario gives a starting point to consider other options which are both sustainable and fair. It indicates what people should pay into a public pension system if they want to preserve the current benefit level and retirement age for themselves, and also want to be fair to future generations. If they are not prepared to pay these contributions, then they should accept a reduction in the replacement rate or an increase in retirement age.

\section{Box 1}

\section{Derivation of the fair contribution rate under ageing: retirement age 60}

The assumed sudden decline in fertility in 1981 should affect the contribution rate fully by 2010 as women give birth on average at age 30 . Had the new rule for contributions been immediately applied when the drop in fertility took place, contributions would have increased gradually from 1981 to 2010. As this did not happen, but a reform of rules is implemented only in 2001, two thirds of the total required increase must take effect immediately, and the rest gradually by 2010 . No one is then punished retroactively, but the jump in 2001 is justified to attain a fair path.

For the longevity increase, the time path for fair contributions is derived as follows: the contribution rate has to correspond to longevity at the time when the current average worker will enjoy pension rights. The midpoint of employment is at 40 years of age and the midpoint of retirement at around 70 years, thus the lead in timing has to be 30 years. As longevity will reach its new permanent level in 2050 , the contribution rate increase must be completed by 2020. Assuming that the new rule is implemented only in 2001, the contribution rate must immediately jump by $3 / 5$ of the total increase.

The scenario in Figure 1 and Scenario 1 in Table 3 show the result for the combined effects of these two rules on the contribution rate. 


\section{Figure 1}

\section{A pre-funded DB system: fair contributions, retirement age 60}

Contributions are gradually increased to 38 percent for intergenerational fairness. Otherwise, in a pure PAYG, the contributions to be paid by future generations would increase to 45 percent.

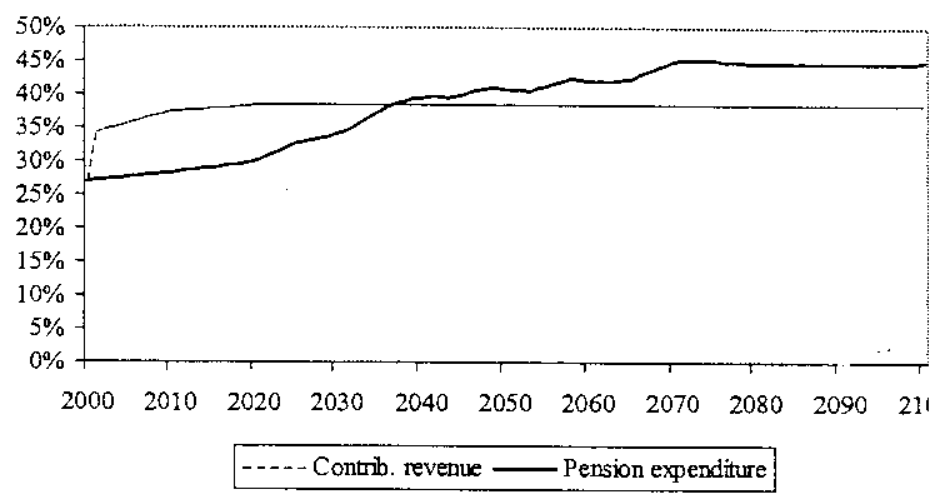

The initial increase in contribution rates produces an asset accumulation which provides interest revenue to support pension financing.

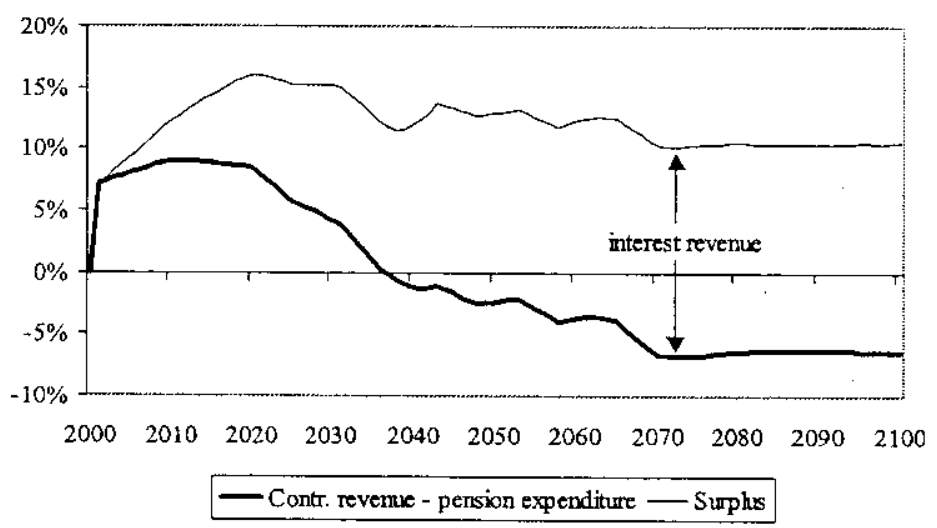

The assets converge to more than 400 percent of the wage bill, or 175 percent of GDP.

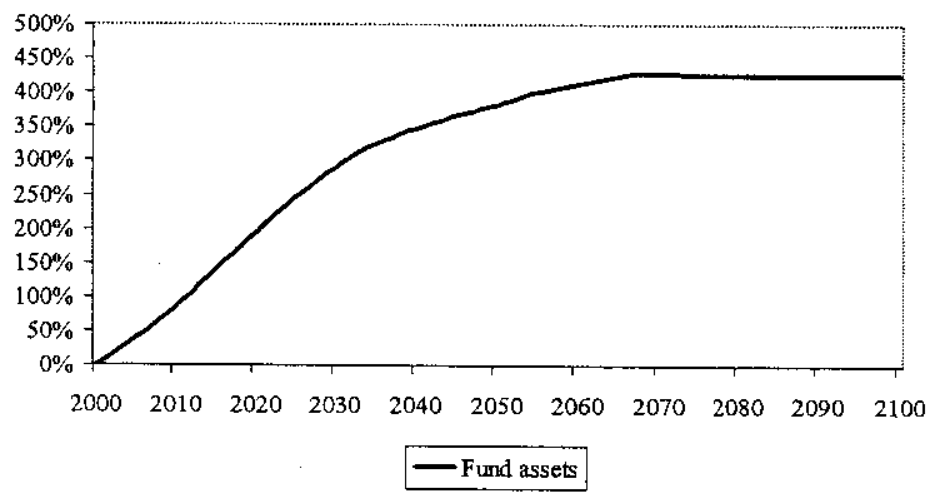

Fertility declines to 1.7 in 1981 ; longevity increases gradually from 78 in 2000 to 83 in 2050; contributions increased in 2001 and gradually further to 2020 to correspond to the fertility decline and longevity increase (Scenario 1 in Table 3). 


\subsection{Further reforms to a pre-funded DB system}

\section{Indexation to prices or decrease of accrual rate}

We have so far assumed that pensions are indexed to the wage rate, as they were until recently and still are in many countries. Lately, however, shifting from wages to prices has been implemented in a few EU Member States and elsewhere. The effect of this change in indexation can be calculated as follows: if the real wage rate is assumed to increase by 1.75 percent p.a. and time in retirement is assumed to reach 23 years after the projected longevity increase, this shift in the indexation rule decreases pension expenditure by 17 percent in the long term, to 37.0 percent of the wage bill. Entry pensions are still 60 percent, but average pensions are 50 percent of wages. The pension of an 82-yearold would be 33 percent lower than in the case of wage indexation.

This shift in the indexation rule has the perverse effect that the lower the growth of productivity in the economy, the smaller the decrease in pension expenditure as a percentage of the wage bill, while the need for a downward adjustment might be even greater in the case of low growth.

Secondly, a change in the indexation rule has a marked effect because it affects pensions retroactively in the sense that even pensions in payment are reduced as compared to original expectations based on wage indexation. Yet this has been politically acceptable as indexation is not commonly understood to be a part of acquired rights in DB systems, untouchable by policy measures. However, the lack of a firm rule may later lead to decisions to increase pensions to restore their relative level. This may become more likely as pensioners will represent an increasing proportion of voters.

For these reasons we now consider an alternative policy measure, namely decreasing the accrual rate. A decrease in the accrual rate from 1.5 percent to 1.25 percent and maintaining the indexation to wages reduces the replacement rate to 50 percent and pension expenditure to 37.4 percent of the wage bill in the long run. Thus, the effect is almost exactly the same as for the shift in the indexation rule if the real wage increase is 1.75 percent. The advantage of accrual rate reduction combined with maintaining wage indexation is that its effect does not depend on future increases in real wages.

Although the long-run effects of these alternative measures are the same, their short- and medium-run effects differ. If accrual rates are reduced only for the accumulation of new rights with no retroactive effect, in the first decades a smaller downward effect results than under indexation change. The difference peaks in 2014 at 3.1 percent of the wage bill. 
Table 3

Reforming a defined benefit system

\begin{tabular}{|l|r|r|r|r|r|}
\hline & \multicolumn{5}{|c|}{ Scenario } \\
\cline { 2 - 7 } & \multicolumn{1}{|c}{$\mathbf{1}$} & $\mathbf{2}$ & $\mathbf{3}$ & \multicolumn{1}{c|}{$\mathbf{4}$} & \multicolumn{1}{c|}{$\mathbf{5}$} \\
\hline Retirement age & 60 & 63 & 63 & 63 & 63 \\
Accrual rate 2001 on- & 1.5 & 1.25 & 1.25 & 1.25 & $1.5 /$ \\
wards, standard & & & & & 1.25 \\
Accrual rate for 60-62 & - & moder- & full & low & moder- \\
year old & & ate & comp. & comp. & ate \\
Entry repl. rate peak & - & 69.3 & 72.9 & 65.7 & $71.6 /$ \\
(2010-14) & & & & & 63.4 \\
Av. repl. rate in nss* & 60 & 60.8 & 64.4 & 56.0 & 60.8 \\
Pension expendit. in nss* & 44.8 & 36.8 & 39.0 & 33.9 & 36.9 \\
Contribution rate in nss* & 38.4 & 32.0 & 33.6 & 29.9 & 31.6 \\
Surplus, max & 16.1 & 12.6 & 14.0 & 10.6 & 12.8 \\
Year of peak surplus & 2020 & 2018 & 2011 & 2018 & 2028 \\
Surplus in nss* & 10.5 & 7.6 & 8.5 & 6.5 & 8.3 \\
Fund in nss* & 427 & 313 & 348 & 265 & 340 \\
Imp. Pens. Debt in nss* & 1092 & 891 & 943 & 821 & 891 \\
IPD - fund in nss* & 665 & 579 & 595 & 556 & 551 \\
Degree of funding, \% & 39.1 & 35.0 & 36.9 & 32.3 & 38.2 \\
$*$ nss = new steady state. & & & & & \\
\hline
\end{tabular}

Under the assumption of stationary population IPD was $610 \%$. - All figures except fertility and degree of funding are expressed as a percentage of the wage bill. - Rough approximation for figures expressed as percentage of GDP obtained by multiplying by 0.4 . Assumptions: Fertility declines to 1.7 in 1981; longevity increases gradually from 78 in 2000 to 83 in 2050. - Pensions are indexed to wages. - Interest rate $r=$ wage bill growth + $1.5 \%$. - Real wage growth $1.75 \%$ and inflation $1.5 \%$ (relevant only for surplus or deficit figures).

Scenarios: 1: Retirement age 60 ; accrual rate $1.5 \%$ per year; contributions increased in 2001 and further to 2020 to correspond to the fertility decline and longevity increase (Figure 1). - 2: Retirement age increases gradually to 63 by 2010 ; standard accrual rate 1.25 $\%$ per year; accrual rate for years $60-62$ provides moderate compensation; contributions increased in 2001 by $2 / 3$ of the total increase to steady state level; the rest gradually accomplished by 2010 (Figure 2). - 3: Like Scenario 2 but accrual rate for years 60-62 provides full compensation. - 4: Like Scenario 2 but accrual rate for years 60-62 provides low compensation. - 5: Two groups: (1) workers born before 1951 maintain original DB rights and get moderately compensated for years 60-62 at work; contribution rate maintained at $27 \%$; (2) workers born 1951 or after: DB accrual rate reduced to $1.25 \%$ per year retroactively from 1981; moderately compensated for years 60-62 at work; new contribution rate effective from 2001 . 


\section{Increasing retirement age}

In addition to increasing pension contributions and reducing benefits, increasing the retirement age is a way of restoring sustainability and fairness, though achieving this under alternative pension systems is not a simple issue.

If workers have a choice about their retirement age, the incentives to retire may matter significantly (for evidence, see Brugiavini, Peracchi and Wise, 2002). In addition, employers may not have the incentives to train and recruit older workers as this investment is at risk due to possible retirement. These factors may go together: the employer may expect the older worker to stay longer only if the pension system clearly rewards late retirement.

For simple numbers it is useful to calculate the actuarially correct compensation in terms of the accrual rate over an additional year at work assuming the initial 40-year work career and 18 years in retirement. It is by definition an increase in the replacement rate such that the capitalised value of the pension - taking one additional year of contribution payments into account - is the same before and after the increase in retirement age. The outcome can then be compared to a case where the initial 1.5 percent accrual rate is applied, leading to a replacement rate of 61.5 percent.

The result depends on the assumption of the discount rate used for determining the actuarially correct compensation. A simple benchmark is a case where the interest rate is equal to wage rate change. The result is that the actuarially correct replacement rate is 65.1 percent, i.e. 5.1 percent should be accrued in the additional year.

If the interest rate is higher than the growth rate of wages, the actuarially correct accrual rate is correspondingly higher. Table 4 gives the results for interest rates 5 percent, 3 percent, 1.5 percent, 0 percent, and -0.7 percent above the wage rate change. The last case is that of an NDC system under ageing, where the number of workers declines by 20 percent over a generation, or by 0.7 percent a year.

Any deviation from the actuarially correct compensation for additional work can be treated as an implicit tax. If the replacement rate does not increase at all, then the implicit tax rate is 100 percent. If the standard 1.5 percent accrual rate is applied to the additional year, then the system reaps $70-80$ percent of the additional revenue (last column in Table 4). Obviously, the figures for the second and further additional years at work or for an increasing life expectancy would be slightly different, but the difference between the compensation determined by the standard accrual rate (or no compensation) and the actuarially fair compensation is always significant. 
Table 4

Actuarially correct compensation for a one-year retirement age increase

\begin{tabular}{|r|l|l|}
\hline \multicolumn{1}{|c|}{$\mathbf{1}$} & $\mathbf{2}$ & $\mathbf{3}$ \\
\hline 5 & 7.8 & 80.9 \\
3 & 6.7 & 77.5 \\
1.5 & 5.9 & 74.4 \\
0 & 5.1 & 70.7 \\
-0.7 & 4.8 & 68.7 \\
\hline
\end{tabular}

$1=$ interest rate premium over wage rate growth,

2 = actuariaily correct accrual rate for an additional year at work,

3 = implicit tax rate if accrual rate is $1.5 \%$ instead of the actuarially correct one for the additional year.

Note: The calculation for implicit tax rate does not include the excess of the wage over the would-be pension during the extra year worked. Were it included, the results for the case of zero for the interest rate premium over wage rate growth, for example, would be $48.4 \%$ instead of $70.7 \%$. However, on balance, it does not include the direct costs related to working rather than retiring, nor the additional utility due to leisure when retired. These may well match the difference between the wage and pension during this one year. Thus, the simple figures for implicit tax rate above may give a good approximation of the relevant factors.

Assumptions: - initially, people are at work from age 20 to 59 and in retirement from 60 to 78. - standard accrual rate $1.5 \%$ (leading to replacement rate $60 \%$ after 40 years at work). contribution rate $27 \%$ (balancing a pure PAYG under a stationary population).

If a retirement age increase requires that an actuarially fair compensation be paid, then, for example, people would earn a 75 percent replacement rate by working until 63 . In the long run, this would lead to roughly the same pension expenditure as before. Therefore, counterbalancing measures are required, for example a reduction in the accrual rate for prime-age workers or tightening eligibility for disability pensions.

As options in the real world will vary from one case to another, we introduce three alternative assumptions to show the orders of magnitude. Note that in all scenarios we simply assume that there would be demand for this additional labour, leaving the questions about the required training and its cost, etc. outside the present paper.

Taking as the reference the pre-funded DB system with the retirement age at 60 , we assume a gradual increase in the retirement age to 63 by 2010 . Secondly, we assume that, from 2001, the accumulation of pension rights until the age of 60 is decreased to 1.25 percent a year while indexation to wages is maintained. For the additional accrual over the years from 60-62 spent at work, we take a moderate assumption that the new standard accrual rate of 1.25 percent applies to one third of the increase in the retirement age and two thirds give an actuarially fair compensation of 4.8 percent. 
These assumptions lead to the entry replacement rate peaking in 2010 at 69 percent. These figures are influenced by the accrual rate of 1.5 percent until 2000 and increased years at work. Later, the replacement rate declines to 61 percent, almost the same as until 2000 (Scenario 2 in Table 3). Pension expenditure settles at 36.8 percent in the long term.

The principle of fairness is now applied to determine the contribution rate from 2001 onwards. Earlier we made it increase gradually until 2020, reflecting both fertility and longevity. Now, as we assume that people work extra years, so that the ratio between years at work and in retirement increases, and as they are not fully actuarially compensated for this, there is no simple rule for the pace of adjusting the contribution rate to reflect longevity change. As a rule of thumb, the new permanent contribution rate is set to be reached by 2010 , and two thirds of the increase takes place in 2001. The result is that for financial sustainability the contribution rate should be increased to 30.4 percent in 2001 and to 32.0 percent by 2010 (Figure 2 and Scenario 2 in Table 3). The surplus peaks in 2018 at 12.6 percent of the wage bill. The fund increases to 313 percent of the wage bill.

As a conclusion, a combination of postponing retirement by three years, increasing the contribution rate from 27 percent to 32 percent, and adjusting the accrual rate downwards for the standard years, and upwards for working from $60-62$, renders the DB PAYG system sustainable under the projected ageing. The emerging fund is smaller than in the case of fixed retirement age, but it is still considerable. It is important that the immediate gains from increased contribution revenue and reduced pension expenditure over the period when people postpone retirement are not given away as lower pension contributions, as the rules of a pure PAYG prescribe, but rather are accumulated into a fund. ${ }^{9}$

The assumption on the additional compensation for working extra years is crucial in this scenario. In Box 2, referring to Table 3, we report three additional scenarios to show the sensitivity of the results in this respect. ${ }^{10}$

9 Breyer and Kifmann (2003) also reach this conclusion while opposing most other arguments for partial funding.

10 We confine our comments here to actuarially correct compensation as an incentive for working more years. For a more profound treatment of flexible retirement, see Simonovits (2003). 


\section{Figure 2}

\section{Pre-funded DB system: standard accrual rate reduced and retirement age increased}

As retirement age increases, pension expenditure initially falls even below the previous level.

This and an increase in the contribution rate produce a comfortable surplus...

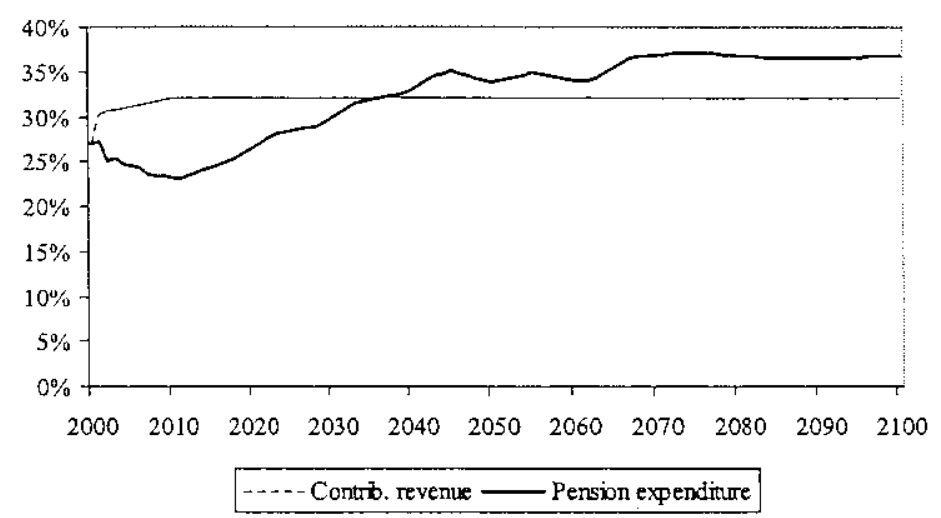

... so that in the more distant future, the burden is considerably eased by the interest revenue ....

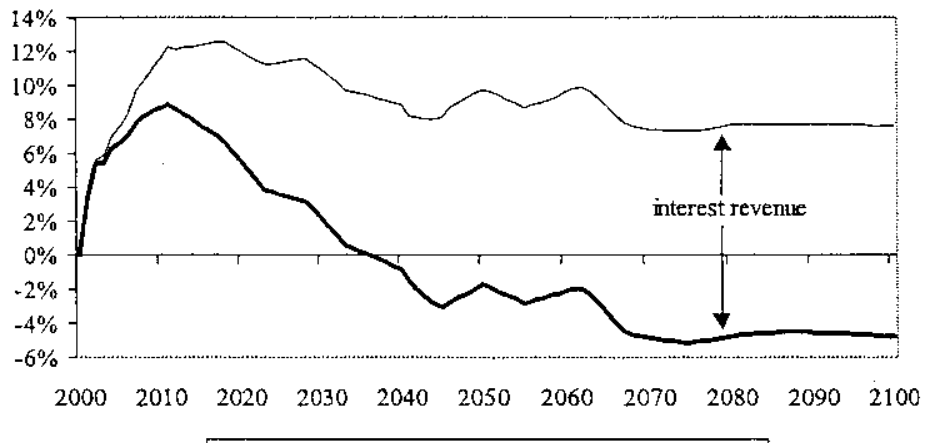

- Contr. revenue - pension expenditure - Suplus

... coming from a fund which grows to over 300 percent of the wage bill.

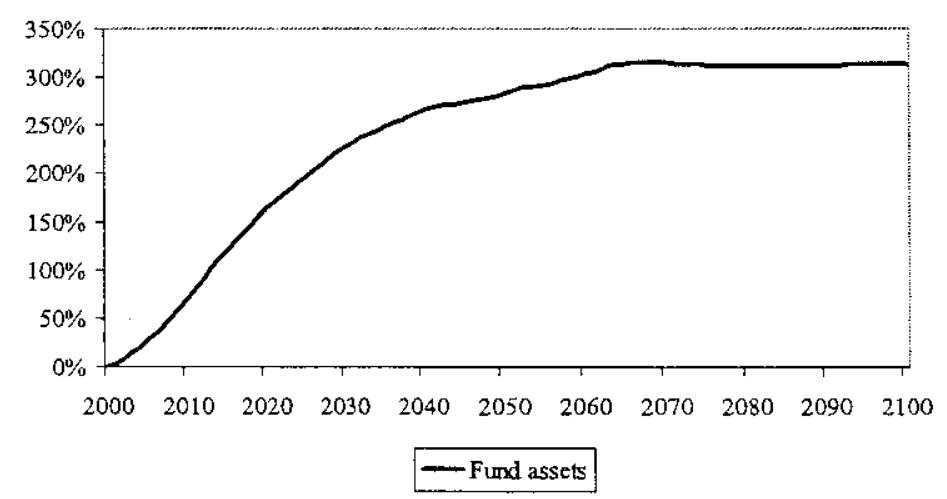

Accrual rate 1.25 percent per year; retirement age increases gradually to 63 by 2010 ; accrual rate for years 60-62 provides moderate compensation; contributions increased in 2001 by $2 / 3$ of the total increase to steady state level by 2010 (Scenario 2 in Table $3)$. 


\section{Box 2}

Outcomes of the reforms with varying compensation for later retirement

In Scenario 2 in Table 3 a moderate compensation for postponing retirement until the age of 63 was assumed. In Scenario 3 a full actuarial compensation is assumed to be necessary. In this case the entry replacement rate peaks at 73 percent, the contribution rate needs to be increased to 33.6 percent, and the fund reaches 348 percent of the wage bill.

In Scenario 4 it is assumed that the effective retirement age can be increased by one year without any compensation at all (reducing disability pensions), the second additional year is compensated only by the standard accrual rate of 1.25 percent, and only the third needs the full actuarial compensation. In this case the entry replacement rate peaks at 66 percent, the permanent contribution rate is 29.9 percent, and the fund reaches 265 percent of the wage bill. Scenario 5 demonstrates that the model used here can be easily extended to more complex cases. Employees born before 1951 maintain the accrual rate of 1.5 percent, while the rate for those born after 1950 is retroactively reduced to 1.25 percent for pension rights earned since 1981 to reflect their low fertility. Both groups receive the moderate compensation for increasing the retirement age. The first group continues to pay the old contribution rate of 27 percent. Now that the differentiation is made in the accrual rates, we simply assume that the required raise in the contribution rate paid by the second group is implemented immediately in 2001. In this case the new constant contribution rate to guarantee sustainability is 31.6 percent, i.e. not much lower than the 32.0 percent in the corresponding case with no retroactive effect. The fund reaches 340 percent of the wage bill. After the increase in retirement age, the pensions for the first group are 71.6 percent while those for the second are 63.8 percent.

\subsection{Partial privatisation of a pre-funded DB system}

In the examples where the retirement age increases, the size of the fund to be reached in about 60 years varies between 265 percent and 348 percent of the wage bill, or roughly between 100 percent and 140 percent of GDP. It is even higher in the base case with constant retirement age.

These amounts of accumulating funds trigger a question as to their management. First and foremost, it is essential for the whole purpose of funding that these funds are not used for government consumption, because in that case the savings in the pension system would not be transferred to future generations. This requirement is met if government consumption and transfers other than pensions are financed from general tax revenue. However, this leaves many options for placing the pension system surplus. If the government has a high initial debt, it may use the pension system surplus for its amortisation. Also, a special public sector pension fund could be established, which would place the 
funds in a wide range of assets, or a public-private-sector partnership could be established for the same purpose. ${ }^{11}$

In addition to these options, under which the funds would be managed by the public sector, management can be fully or partially shifted to the private sector for political, institutional or economic reasons, not to be discussed here. This could be done by diverting a percentage of the contributions to the privately managed second pillar, and correspondingly reducing the accrual of DB benefits in the public pillar.

As an illustration, we start with the basic mono-pillar case where retirement age is maintained at 60 and the contribution rate is increased to 38.4 percent by 2020 . This scenario results in a fund of 427 percent of the wage bill. This case is reproduced as Scenario 1 in Table 5, which reports results for privatisation.

Let's now assume that from 2001 onwards 4 p.p. of the contributions are diverted to a newly created, privately managed and fully funded second pillar. The standard assumption of the interest rate, $r=w b+1.5$ percent, holds for both pillars.

If the accrual rates in the DB first pillar are reduced only pro rata, i.e. in proportion to the decline in contributions paid to the first pillar, the result is an unsustainable first pillar, even though the initial mono-pillar was sustainable. Thus, sustainability requires more than a pro rata reduction in the accrual rate in the first pillar, such that the total replacement rate remains at the initial level (or a further increase in the contribution rate or a transfer from somewhere). ${ }^{12}$

Reducing the accrual rates in this manner, the first pillar remains sustainable, and the main effect of the privatisation is that in the long run it shifts a fund of 159 percent of the wage bill from the first pillar to the second. The total of funds in the two pillars is the same as in the mono-pillar, as the first pillar maintains a fund of 262 percent. This is Scenario 2 in Table 5. The first pillar does not encounter a deficit at any point in time as the 4 p.p. of contributions diverted to the second pillar is less than the increase in the contribution rate in 2001. Later, contribution revenue for the first pillar is less than pension expenditure, but the revenue from assets accumulated in the first decades more than

11 If in such a case the system is a DB one, it is classified in national accounts under the general government, as is the case for example in Finland; this is relevant for public finances monitoring under EMU.

12 The key to understanding this is once again the concept of implicit tax explained in Chapter 2: under privatisation, the accrual rate in the first pillar has to be adjusted downwards in the proportion determined by the ratio of the contributions shifted to the second pillar to the initial contributions less the implicit tax. - For an illustration of this condition under a stationary population, thus displaying the pure effect of privatisation, see Section 2.4 in Oksanen (2002). 
covers this. The first pillar remains sustainable, with the said assets amounting to about 70 percent of GDP. ${ }^{13}$

As a second illustration we take the mono-pillar case where retirement age increases to 63 , rendering it sufficient that the contribution rate increases to 32 percent by 2010 and the fund reaches 313 percent of the wage bill. It is reproduced as Scenario 3 in Table 5.

Diverting a 4 p.p. contribution into a second pillar and again reducing the accrual rate in the first pillar to maintain sustainability (Scenario 4 in Table 5) still maintains the first pillar in surplus throughout the scenario (apart from a small deficit in 2001). The permarient level of funds reaches 153 percent of the wage bill.

The remaining surplus in the first pillar in these two cases means that an even bigger shift to the second pillar is possible. In the case of a retirement age of 63, diverting 8 p.p. of contributions to the second pillar leads to a balance in the first pillar in the long run (Scenario 5 in Table 5 and Figure 3). In this way assets are accumulated in the second pillar which acquires a permanent fund of 318 percent of the wage bill. Now, a problem of at least a temporary deficit in the first pillar arises. A deficit of about 5 percent of the wage bill ( 2 percent of GDP) appears immediately in 2001, decreasing to zero by 2010 , thanks to the increase in the retirement age adding to revenue. After 2010 the balance fluctuates around zero.

In this last scenario, the degree of privatisation was chosen so that no funds were left to the first pillar. Greater privatisation, again with the principle that the accrual rates in the first pillar are reduced so that the total replacement rate is maintained, would lead to debt accumulation in the first pillar. This could still represent a sustainable path where deficit and debt each converge to some proportion of the size of the economy.

As a separate issue, the effect of an alternative assumption on the rate of return on second pillar funds is reported at the bottom of Table 5 , combined with any of the privatisation scenarios. Should this rate be 3 p.p. above the wage bill growth instead of the standard assumption of 1.5 p.p., the effects on the total replacement rate and on the permanent level of funds are noticeably higher.

The degree of funding, i.e. the ratio between accumulated funds and IPD, reported in Table 5, is in the mono-pillar case with retirement age at 60 around 40 percent in all cases. In the cases where retirement age increases to 63 , the resulting degree of funding varies in the range of 35-40 percent after full ad-

13 Were the assumed uniform interest rate higher (lower), accumulation of assets in the second pillar and the corresponding reduction in the first pillar assets would be larger (smaller) leaving total amount assets unaffected. The surplus in the first pillar would also change, as would division of the total replacement rate between the two pillars. 
Table 5

Partial privatisation of a pre-funded Defined Benefit system

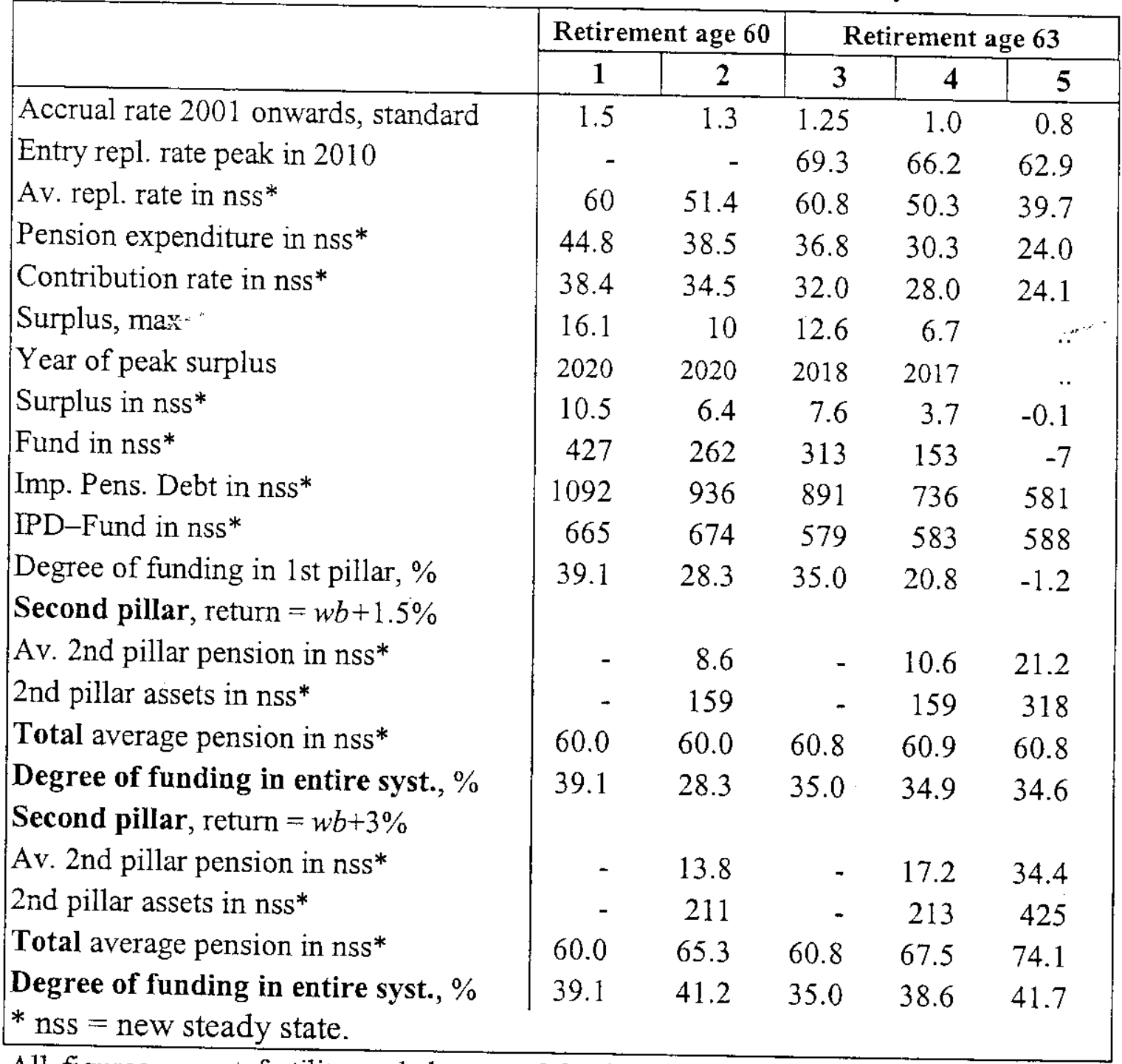

All figures except fertility and degree of funding are expressed as percentage of the wage bill. - Rough approximation for figures expressed as percentage of GDP obtained by multiplying by 0.4 .

Assumptions: Fertility declines to 1.7 in 1981; longevity increases gradually from 78 in 2000 to 83 in 2050 . - Pensions indexed to wages. - Interest rate in the first pillar $r=$ wage bill growth $+1.5 \%(=w b+1.5 \%)$ - Real wage growth $1.75 \%$ and inflation $1.5 \%$ (relevant only for the surplus and deficit figures).

Scenarios: 1: Retirement age 60; mono-pillar, accrual rate $1.5 \%$ per year; contributions adjusted for intergenerational fairness (same as Scenario 1 in Table 3 and Figure 1). 2: 4 p.p. of contributions in Scenario 1 diverted to the second pillar from 2001 onwards; second pillar rate of return $w b+1.5 \%$, or $=w b+3 \%$. 3 : Retirement age increases gradually to 63 by 2010 ; mono-pillar, standard accrual rate $1.25 \%$ per year; working at 60-62 moderately compensated; contributions adjusted for intergenerational faimess (same as Scenario 2 in Table 3). 4: 4 p.p. of contributions in Scenario 3 diverted to the second pillar from 2001 onwards; second pillar rate of return $w b+1.5 \%$, or $=w b+3 \% .5: 8$ p.p. of contributions in Scenario 3 diverted to the second pillar from 2001 onwards; second pillar rate of return $w b+1.5 \%$ (Figure 3), or $=w b+3 \%$. 


\section{Figure 3}

\section{Partial privatisation of the pre-funded DB system: Retirement age 63}

Diverting 8 p.p. of contributions to the second pillar reduces first pillar revenue to the level of expenditure in the long run ...
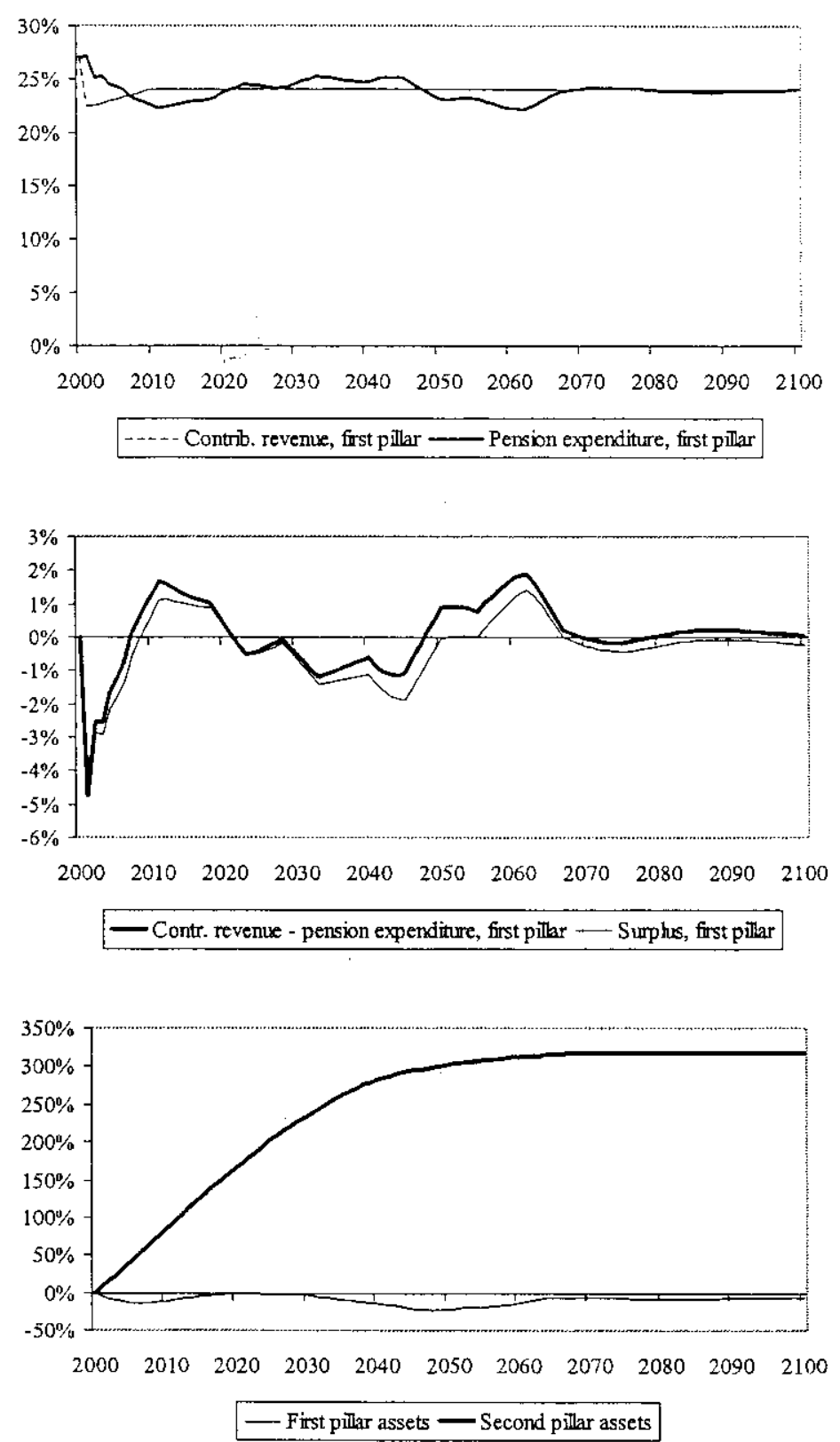

- First pillar assets - Second pillar assets

No reserves are accumulated in the first pillar, but the second pillar funds grow to more than 300 percent of the wage bill.

... maintaining a balance close to zero in the long run, while a significant deficit occurs in the first decade, as it is assumed that the retirement age increases only gradually, helping to restore the balance only after a decade.

Eight percentage points of contributions in Scenario 3 diverted to the second pillar from 2001 onwards; second pillar rate of return $=w b+1.5 \%$ (Scenario 5 in Table 5).

justment. About $2 / 3$ of the accumulation of funds should take place in 30 years.

The implications of pension system privatisation for public finance targets will be discussed in Section 5.2 below. 


\section{Transition to notional defined contribution system}

As described in Section 2.2, the NDC is a system where contributions are fixed, registered in notional individual accounts which are remunerated by an administratively fixed rate of interest, and the capitalised value at retirement is transformed to an annuity paid out as a pension. ${ }^{14}$ The main advantage of this system is that pension expenditure adjusts to contributions in the long run if the notional rate of interest equals the wage bill growth, and if the longevity projections used for determining the annuities are continuously revised to reflect reality.

Under these assumptions, however, it is only pension expenditure which adjusts to contributions in the long run. A full financial balance is generally not reached, because a change, for example in the rate of growth of the number of employed caused by a change in the participation rate, migration or retirement age, will always cause an initial discrepancy between pension expenditure and contribution revenue. Even if only temporary, it leads, if not corrected by a specific rule or measure, to an explosive accumulation of liability or asset stocks (under the conventional assumption that the market rate of interest exceeds the contribution revenue growth rate). Thus, the basic rules of an NDC system always need to be accompanied by an additional adjustment mechanism, for example, a transfer from (or to) the government budget or a modification to one or another of the system's parameters. ${ }^{15}$

We consider an NDC system on the basis of the conventional rule that the internal rate of interest is wage bill growth, without anticipating its future changes. Contributions are fixed at their level of 27 percent of wages in 2000.

The first two scenarios in Table 6 assume that the retirement age remains at 60 . In Scenario 1 the transition to NDC takes place in 2001 so that all previously accumulated $\mathrm{DB}$ pension rights are fully respected, while everybody starts to earn NDC rights from 2001 onwards. Wage bill growth is set as the notional interest rate (nir) for the individual accounts. For technical reasons related to the model used, it is assumed that indexation of DB pensions will also shift from wage rate to wage bill growth.

In the long run, the level of entry pensions declines to 40 percent of the wage and the average pension to 36 percent (the latter being lower than the former

14 NDC reforms were implemented in the 1990s in Sweden, Latvia and Poland and in some nonEuropean countries (Palmer, 2000, Williamson, 2001, and Vanovska 2004). The reforms in Italy in the 1990s also contain some NDC features (Marè and Pennisi 2004, and Brugiavini and Galasso 2003).

15 For example, an adjustment mechanism is needed in the Swedish system because the rate of change of the average wage rate rather than of the wage bill is used as the notional interest rate (Settergren 2001a). 
because pensions are now indexed to the wage bill rather than the wage rate), and pension expenditure is covered by revenues. However, this transition option first leads to deficit, pension expenditure minus revenue peaking at 4 percent of the wage bill in 2040, and the balance is reached only in the 2060s when all DB rights have ceased and the population has reached a steady path. Amplified by the interest on the accumulating debt, the debt is then 131 percent of the wage bill. Avoiding this requires an average subsidy of 1 percent of the wage bill from general government over 2001-2068.

In this scenario, for a long time after 2001 workers do not have much of an incentive to postpone retirement. Initially, working an extra year only increases the pension by about the same amount as in the old DB system, or the implicit tax rate on the extra effort is about 70 percent (see Section 3.4), and the incentives for later retirement will only emerge very slowly as the NDC component grows.

\section{Transforming accumulated DB rights to NDC accounts}

As a result of these problems, transition to NDC has been implemented following a rule whereby accrued pension rights of those born before a given year are retroactively transformed into NDC rights, while the oldest workers are kept in the old DB system. An 'in-between' group can also exist, with part of accrued rights kept in the DB system and part transformed into NDC rights. ${ }^{16}$

In Scenario 2 in Table 6, workers born before 1951 stay in the old system. Still assuming retirement at 60 years, they will all have retired by 2011 . The accrued pension rights of those born after 1950 are transformed to initial entries in their NDC accounts.

Both over the transition period on average and in the long run, this option leads to equality of pension expenditure and revenue, and to the level of pensions outlined above. The first NDC pensions in 2011 are 54 percent of the wage rate, thus markedly lower than the last DB entry pensions of 60 percent still paid in 2010 to the last cohort in the old system. Under our stylised assumptions this can be regarded as fair as the latter group initiated the reduced fertility (in practice, fertility never declines suddenly, and the transition rule should te made gradual).

16 In the Swedish reform implemented in 1999, workers born before 1938 stayed in the old system, those born in 1954 or after were fully shifted to the NDC, and those in between received a pension calculated with moving proportions from both systems (Palmer 2000, 19). In the Latvian NDC reform implemented in 1996, the notional initial capital was arbitrarily based on the number of years of service before 1996 and the monthly average contribution wage in 199699. Several policy changes have since been adopted to eliminate the effects of particular factors like unemployment or non-reporting by employers (Vanovska 2004). 
Table 6

Transition to NDC

\begin{tabular}{|c|c|c|c|}
\hline & \multicolumn{3}{|c|}{ Scenario } \\
\hline & 1 & 2 & 3 \\
\hline $\begin{array}{l}\text { NDC pillar } \\
\text { Retirement age } \\
\text { Nr of groups }\end{array}$ & $\begin{array}{r}60 \\
1\end{array}$ & $\begin{array}{r}60 \\
2\end{array}$ & $\begin{array}{r}63 \\
2\end{array}$ \\
\hline First NDC entry pensions & $0+$ & 54.1 & 72.7 \\
\hline Av. pension in nss* & 36.1 & 36.1 & 44.7 \\
\hline Assets or Debt (-) in 2068 & -131 & -11 & 39 \\
\hline Required av. subsidy 2001-2068 & 1.1 & 0.1 & -0.3 \\
\hline Imp. Pens. Debt in nss* & 642 & 642 & 642 \\
\hline Second pillar, return $w b+1.5 \%$ & & & \\
\hline Av. pension in nss* & 8.5 & 8.5 & 10.5 \\
\hline Assets in nss* & 157 & 157 & 157 \\
\hline Total average pension in nss* & 44.6 & 44.6 & 55.2 \\
\hline Second pillar, return $w b+3 \%$ & & & \\
\hline Av. pension in nss* & 13.7 & 13.7 & 17.1 \\
\hline Assets in nss* & 207 & 207 & 210 \\
\hline Total average pension in nss* & 49.8 & 49.8 & 61.8 \\
\hline
\end{tabular}

All figures except fertility are expressed as a percentage of the wage bill.

Rough approximation for figures expressed as percentage of GDP obtained by multiplying by 0.4 .

Assumptions: Fertility declines to 1.7 in 1981; longevity increases gradually from 78 in 2000 to 83 in 2050 . - Interest rate $r=w b+1.5 \%$. - Contributions fixed at $27 \%$. - Notional interest rate (nir) set to follow wage bill growth.

Scenarios: 1: Retirement age 60; previous DB rights respected, all move to NDC in 2001. 2: Retirement age 60; employees born before 1951 stay in DB; others move in 2001 to NDC with $\mathrm{DB}$ rights transformed to initial entries in their NDC accounts. 3: Retirement age increases gradually to 63 by 2010; transition to NDC like in Scenario 2 (Figure 4).

Second pillar: contribution fixed at $4 \%$; two options for the interest rate on second pillar assets, $r=w b+1.5 \%$ and $r=w b+3 \%$. The second pillar is combined with each of the NDC pillar variants. The last line shows total average pensions from each variant in the new steady state. 


\section{Increasing retirement age}

Although under the assumed NDC rules an increase in retirement age leads in the long run to an equal increase in pension expenditure and contribution revenue, it also has an additional positive effect: pension expenditure first decreases transitionally, while contributions increase, thus producing a surplus.

To show this effect, we assume in Scenario 3 that the retirement age increases gradually from 60 in 2000 to 63 in 2010, while otherwise maintaining the assumptions of Scenario 2. This assumption is backed by incentives as the workers transferred to the NDC system will, if they postpone retirement, earn interest on their newly created pension account from the outset. The older workers staying in the old $\mathrm{DB}$ system are assumed to be compensated as in the DB case in Section 3.4 above.

This scenario first leads to a surplus of revenue over pension expenditure, peaking at 3.3 percent of the wage bill in 2011 (see Figure 4). Later, deficits also occur, but on average over 2001-2068 the surplus is 0.3 percent. The entry replacement rate for the DB pensions increases to 71.5 percent in 2010, and the first NDC entry pensions in 2014 are 73 percent of the wage rate. Later, as the system reaches a steady path, entry pensions are 48 percent, and average pensions 45 percent of the wage.

\section{Second pillar attached to an NDC reform}

NDC reforms are in most cases accompanied by the introduction of a fully funded second pillar for those transferred to the new system. The motivation is to add to future pension levels as the NDC reform reduces them, depending on the assumption of the retirement age, to $36-45$ percent.

In Table 6 we assume that on top of the 27 percent contribution to the NDC system, a contribution of 4 percent of wages is paid to a fund. This takes the total contribution rate to 31 percent, or roughly to the level of the DB reform scenarios with the retirement age increase (Table 3, Scenarios 2-5).

In the early years, the financial surplus in the second pillar is more thain 4 percent of the wage bill (contributions plus interest revenue). The fund grows to a permanent size of 157 percent of the wage bill. The average pensions provided by this pillar to those who have contributed to it over their whole career are 8.5 percent or 10.5 percent of wages, depending on whether people worked for a total of 40 or 43 years. Another assumption on the interest rate, a 3 p.p. premium over wage bill growth, gives a more than 6 p.p. higher replacement rate than in the previous cases; combined with a retirement age of 63 , it restores the level of total pension to above 60 percent. 


\section{Figure 4}

\section{Transition to NDC}

As retirement age increases, contribution revenue first exceeds pension expenditure, and a surplus is produced.

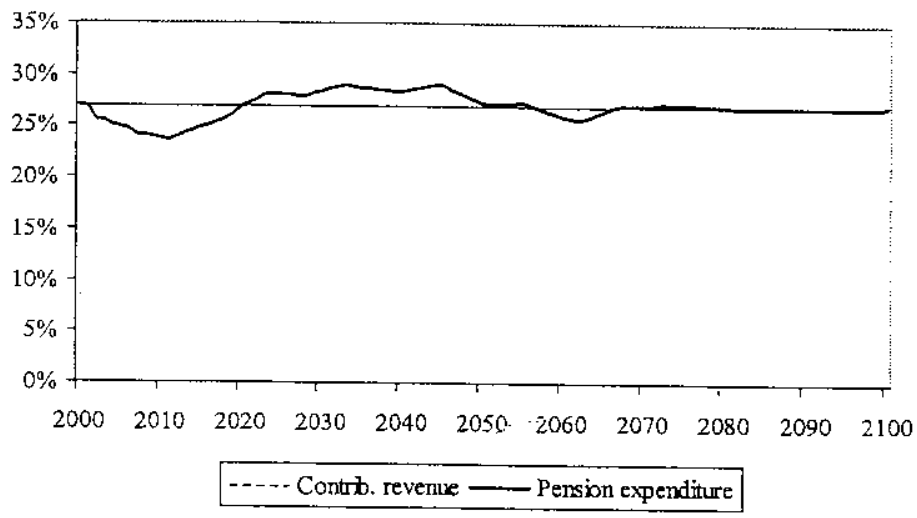

Then, the balance reverses, but ultimately the system reaches the long-run balance.

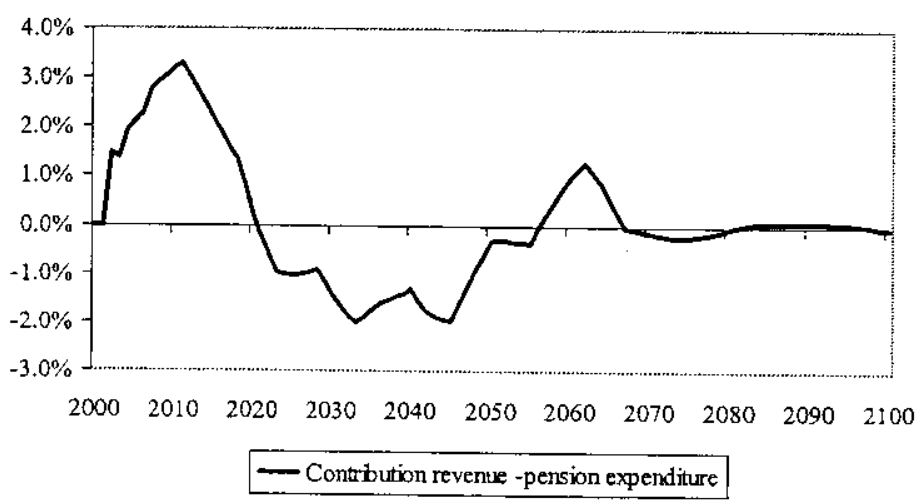

Entry replacement rates in the first pillar rise initially to above 70 percent, but then decline, leading together with the second pillar, to total entry pensions of 60 percent and total average pension of 55 percent.

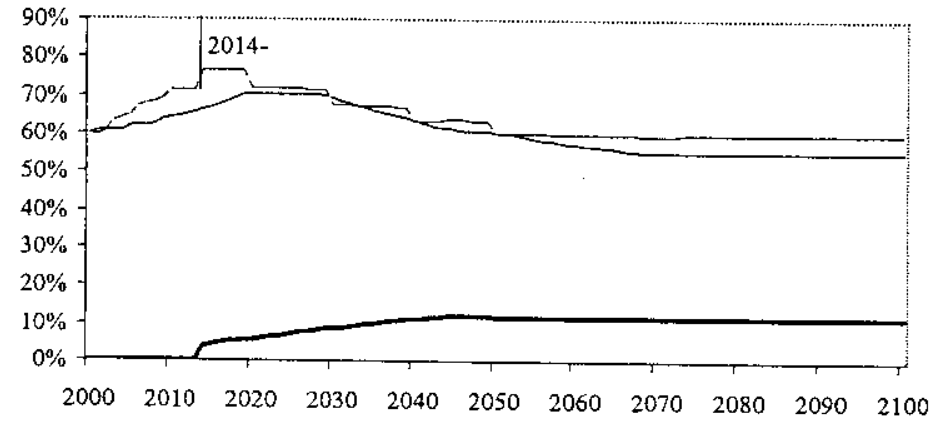

- Total average pensions ----- Total entry pensions - Entry pensions, 2nd pillar

Total entry pensions: DB until 2013 and NDC 2014- plus $2^{\text {nd }}$ pillar pensions.

Retirement age increases gradually to 63 by 2010 ; employees born before 1951 stay in $\mathrm{DB}$, others move in 2001 to NDC with $\mathrm{DB}$ rights transformed to initial entries in their NDC account (Scenario 3 with second pillar return of wb+1.5\% in Table 6). 
Figure 4 illustrates Scenario 3 in Table 6 combined with the second pillar, assuming the rate of return to be $w b+1.5$ percent. The first NDC entry pensions in 2014 are 73 percent of the wage rate, after which they decline and, together with the second pillar, produce a total average pension of 55 percent as the system matures.

\section{Summary of NDC reform}

For careful designing of an NDC reform it should be recognised that, in practice, no NDC rules guarantee full financial balance in all normal circumstances as there is no way to anticipate with simple rules all factors which cause a deviation from full balance. Financial balance depends, for example, on the retirement age and therefore on the behaviour of workers, and of employers as providers of jobs. Therefore, transfers from or to the general public sector budget or rules to change the parameters of the system according to emerging imbalance are needed. ${ }^{17}$

These complications should not obscure a significant advantage: an NDC reform provides a good basis for achieving long-term sustainability. If the notional rate of interest is equal to the increase in the wage bill, pension expenditure and contribution revenue are equal in the very long run. This is a great advantage, enhanced by the simplicity and transparency of this rule, and it can be argued for on the grounds of approximating intergenerational fairness. Furthermore, an NDC system incorporates relatively strong incentives for an increase in retirement age. If this happens, the short-term positive effect on the financial balance of the system helps to meet the otherwise unavoidable costs during the transition.

\section{Main implications for pension reforms and public finance}

\subsection{Comparison between DB and NDC reforms}

The $D B$ system reform outlined above combined all the three key elements: increase in contribution rate, decrease in the standard accrual rate and an increase in retirement age supported by a close-to-actuarially fair accrual rate in the last years of employment.

17 In the Swedish NDC pillar, expenditure will considerably exceed contribution revenue in $2010-2045$, partly caused by the rule that the (basic) internal rate of interest is the rate of change of the average wage rather than of the wage bill. Coverage for this deficit is available, as in 2001 the new system inherited a buffer fund from the former DB system, the size of which was equivalent to pension expenditure over 3.9 years (Settergren, 2001b, and The Swedish Pension System Annual Report 2002, 39), or 27 percent of GDP. Note that this leeway was made available as the Swedish public DB system was partially funded. 
The assumed three year increase in the retirement age and a contribution rate increase from 27 percent to the range of $30-33$ percent restore the replacement rate at around 60 percent, and lead to a permanent fund of 100-150 percent of GDP. The outcome is financially sustainable and, broadly speaking, fair for all generations, taking into account their fertility and longevity.

As considerable funds are accumulated in this scenario, the pension system can be partially privatised, for example, if there is a risk of government using the funds for other purposes and if privately managed institutions are trustworthy. In this case, however, the first-pillar benefits have to be further reduced, which weakens the actuarial fairness in this pillar. Privatisation may also cause a deficit in the first pillar, the size of which depends primarily on the proportion of the system to be privatised and on the pace of implementing the reform and changes in retirement age.

In the NDC reform, pension benefits are automatically adjusted so that in the long run, fixed contributions cover pension expenditure. The transition to the NDC system can be implemented so that workers born after a given year are transferred to the new system so that they receive an initial fund based on their work history. In this case the incentives for working extra years could lead to a retirement age increase which is sufficient for ensuring the financial balance of the system over the transitional period.

Implementing an NDC reform under a shrinking labour force leads to a reduced replacement rate, for example in the stylised NDC scenario to 45 percent, even if the retirement age increases to 63 . This secures financial sustainability of the NDC pillar, but the level of pensions may not be considered adequate. This may trigger the introduction of a second, privately managed pillar.

The illustrated reforms assume a permanent change in fertility. However, uncertainty about its future development does not hamper application of the reform blueprints: if fertility changes again, the framework provides a rule for an adjustment to the DB system contribution rates or benefits to re-establish sustainability. In the NDC system, equality of contributions and pension expenditure is guaranteed in the long run, but adjustment is needed to neutralise the effect of a temporary imbalance caused by a change in the labour force, be it caused by change in fertility or anything else.

Longevity change, if not followed by a proportional increase in retirement age, requires an adjustment to the contribution rate or benefits in a DB system. An NDC system adjusts the replacement rates automatically.

If pensions are indexed to wages in a DB system, neither the sustainability of the system nor replacement rate depend on changes in labour productivity, under the conventional assumption that labour productivity and wages move together in the long run. The same applies to an NDC system via indexation to the wage bill. A 
DB system has more scope for alternative indexing rules, e.g. indexing pensions to prices, which might be part of a pension reform package, with the aim of reducing the average replacement rate. In this case, however, other system parameters may need to be adjusted according to changes in productivity.

\section{Stability and transparency of rules and portability of rights}

In addition to these specific characteristics of a reform of a DB system compared to a transition to an NDC, more general issues exist with regard to designing these reforms and finding a political consensus for their implementation. As DB and $\mathrm{NDC}$ are identical at a very high level of abstraction (as shown in Chapter 2 above), some authors have taken the extreme view that switching to an NDC "would seem to be an unnecessary complication and, ultimately, a dead end" (Disney, 2000). This view disregards the benefits of fixing the contribution rate, and setting transparent rules for determining pension benefits, which together nearly guarantee financial sustainability under a very broad range of eventualities, and treat successive generations roughly equally. The remaining adjustments can be shown to be modest, such that finding a way to secure sustainability should not represent an insurmountable problem.

The high degree of transparency of the NDC rules should be an advantage, combined with the confidence that the rules cannot be switched at will as the personal accounts, even if notional, give a certain ownership to the accumulated pension rights. This enhances the stability of the system, allowing a person in the middle of his work career to know roughly what his/her pension will be after a normal career and thereby to take reasoned decisions on additional pension saving, as a matter of personal choice.

Of course, the other side of this coin is that policy-makers do not have the same flexibility to adjust the system according to unforeseen needs as in a DB system with less well defined pension entitlements. Yet the result of a careful assessment might well be that the NDC system is more attractive than a DB reform because of its inherent automatic adjustment to developments in the demographic structure and the economy, leaving less need for discretionary intervention.

These same features matter also for portability of pension rights. Briefly, an NDC system is more suitable for transfer as it includes individual accounts as a genuine feature. In a DB system the value of the accumulated pension rights requires that the rules of the system be unambiguous. However, even in this case, it might well be that the contributions paid by the individual have not been based on rules which guarantee sustainability of the system. Recognising this, it becomes harder to determine the fair capitalised value of the accumu- 
lated DB rights. To help to do this is another reason to review and adequately change the rules to secure financial sustainability and implement fairness.

\section{Actuarial fairness}

In addition to these features, the $\mathrm{DB}$ and NDC reforms differ with regard to actuarial fairness across different groups of beneficiaries. A prototype NDC system is actuarially fair in the sense that individual accounts earn the administratively set interest rate, and the annuity pension is determined by life expectancy. However, if these parameters are set uniformly for all groups which are known to have different characteristics, e.g. across genders, deviation from full actuarial fairness occurs. A guaranteed minimum pension also has a similar effect.

In a $\mathrm{DB}$ system, the degree of actuarial fairness may vary from zero for a flat-rate pension to a high degree in a system where the pension is determined on the basis of the whole working career wage. Also, the accrual rates for older workers can be adjusted to provide adequate incentives to stay longer at work, and, as was recently the case in Finland, a longevity factor can be inserted to reduce the level of pensions as longevity increases. These changes mimic the good properties of an NDC system. Another such example is the Rürup Commission proposal, published in August 2003, for German pension reform, which introduces a 'sustainability factor' such that an increase in the ratio of contributors to pensioners leads to a certain decline in the replacement rate. The Commission proposed to give it a weighting such that only part of the required adjustment would be covered by this factor, with contribution rates also needing to be increased (Bundersministerium für Gesundheit und Soziale Sicherung 2003, and Börsch-Supan and Wilke 2003).

\section{Pension reform politics}

Perhaps the main difficulty with many DB reforms to date has been that they have not been ambitious enough to meet the challenges caused by population ageing, and the proposals have been further watered down in the political process, which has led to frequent reforms. The result is that people do not accept any proposal, not so much because of the proposal itself, but in order to make their case against any further proposal they fear might be in the pipeline.

To break this deadlock it might be helpful that any reform proposal should cover all important issues, and prepare the system for sustainability and fairness in any eventuality so that people can view it as the one and only negotiation round (although it can be a long process as it was in Sweden). An NDC reform meets this requirement, though it is not impossible that an overall re- 
form which preserves the fundamental characteristics of a DB system for administrative reasons could also do so - though an NDC reform blueprint would certainly be a useful reference scenario in that case too.

\subsection{Effects of pensions and ageing on public finance targets}

It is indispensable that the surplus in the public pension system emerging in any of the pension reform options be inserted into the general government budget balance target. Otherwise, i.e. if this target is set independently of the financial balance of the public pension system, the funds which are supposed to represent a fair transfer for future pensions would immediately leak out either as lower taxes or higher non-ageing-related expenditure.

For a consistent budget target setting, firstly, a benchmark for the balance of public sector revenue and expenditure other than pensions needs to be defined. A simple benchmark is a balance which would maintain the government net debt/GDP ratio as constant since, assuming that no population ageing is taking place, transferring the same debt/GDP from one generation to another treats all generations equally. Note that for simplicity, we disregard old-age-related public expenditure (like heath care) other than pensions.

If we assume that initially government net debt is 50 percent of GDP (as it was for the EU-15 on average in 2001), real GDP growth is 1.6 percent and inflation is 1.5 percent, implying a nominal growth of 3.1 percent (as assumed in our stylised scenarios). Under these assumptions the non-ageing benchmark for the deficit is 1.6 percent of GDP $(=0.031 * 50$ percent; for a country with 100 percent initial net debt, the benchmark deficit would correspondingly be 3.1 percent of GDP, and, obviously, for a country with zero debt, zero).

Secondly, the surplus (or deficit) in any pension reform scenario, expressed above as a percentage of the wage bill, needs to be transformed into a percentage of GDP. A rough estimate is obtained by multiplying them by 0.4 (assuming simply that the wage bill after pension contributions is 40 percent of GDP).

Adding the public pension system surplus to the benchmark deficit of 1.6 percent gives the general government budget target which is consistent with each pension reform option. For example, in the DB mono-pillar scenario in which retirement age increases by three years (Scenario 2 in Table 3 ) the resulting general government budget balance target first gradually increases to around 3 percent of GDP, and then reduces towards 1.5 percent as the new steady state is approached. In this scenario, the surplus in the first decade stems from the reduced expenditure and increased contribution revenue due to later retirement. The important message from this case is that the surplus funds stemming from the increased retirement age should be re- 
tained within public finances. If given away, as would happen in a pure PAYG system or by aiming at a lower target for general government balance, the burden of future expenditure increase would be shifted to future contributors/taxpayers. ${ }^{18}$

If the system is partially privatised and the newly created privately managed entities are classified outside general government in national account statistics, the target for general government balance needs to be reviewed. In the case above, where 4 p.p. of contributions are diverted to a second pillar (Scenario 4 in Table 5) half of the asset accumulation shifts to the latter, and a 0-1 percent surplus target for government finances is implied.

If 8 p.p. of contributions are diverted to the second pillar, the public pension system will accumulate no reserves (Scenario 4 in Table 5). This means that the long-term target for the public sector balance should be close to the initial 1.6 percent of GDP deficit (which is consistent with a constant debt/GDP ratio). The particularly important feature here is that during the initial phase of privatisation, the first pillar suffers from a noticeable deficit. This raises the government deficit to above 3 percent of GDP, and it subsequently only reduces thanks to the assumed increase in retirement age. In such cases, in setting the short- and medium-term budget targets, the accumulation of public-policy-induced compulsory savings in the newly created second pillar needs to be taken into consideration as an alleviating factor. The risk in this scenario is that the retirement age may not increase and that financial sustainability may therefore not be achieved.

Note that the rule described here for a general government budget balance target would equally apply in a situation where some proportion of pension expenditure is regularly covered from the central (or local) government budget, and thereby from general tax revenues instead of pension contributions.

\section{Target setting under a transition to an NDC system}

The basic rule for setting a general government budget balance target under a transition to an NDC is simple. As in the long run, if the NDC internal rate of interest is the wage bill change, pension expenditure will be covered by contribution revenue, the long run target of maintaining the initial net debt can be considered as a first approximation. All the adjustment required by ageing is put on the reduction of the capital value of the pension benefits, and the link between the annuity pension and the retirement is actuarially neutral.

18 For a similar application for overall public finances, using the existing ageing-related public expenditure projections for the euro area, see Oksanen (2003). 
We saw above, however, that in an NDC system, deficits or surpluses occur during the transitional period. Yet if we take the view that the rules for the transition are designed to follow in the best possible way the principle of intergenerational fairness, there is no reason to deviate from the constant general government net debt target even during the transition. Note that this holds independently of whether the temporary deviation from the balance in the NDC pillar is covered by transfers from or to the central government budget or by adjusting the parameters of the NDC system. It is also immaterial for this rule whether the central government, on behalf of the contributors, regularly covers some non-contributory periods such as maternity leave and unemployment. ${ }^{19}$

\section{Conclusions and main thrust of this paper}

In this paper we have shown that the rules of a pension system which seem to work well under a stable demographic structure require a thorough review for an ageing population. It is important to tracing the change in age structure - and, linked to it, the change in the proportion of retirees to working population - to its two fundamental demographic factors, low fertility and increasing longevity, in order to understand the issues at stake and to communicate the necessity of pension system reforms.

In Chapter 2 we showed with a simplistic three-period model that the same principle of fairness between successive generations which is implemented in a pure DB PAYG system under a stable age structure leads to unfair burden-sharing under ageing. The terms of the (implicit) intergenerational pension contract therefore need to be changed already for the first generation which has a lower rate of fertility and is expected to enjoy retirement longer than its predecessors. A new combination of the pension contribution rate, replacement rate and retirement age is called for. Otherwise the increased pension burden will be shifted to future generations and the prin-

19 Thus, the implication of this simple principle for Sweden, which has an initial public net debt of zero, that the target for general government balance should be zero. Two reservations should, however, be expressed: (1) we distegarded the old-age-related expenditures other than pensions; the increase in their share of GDP calls for a surplus if intergenerational fairness is followed, and (2) in national accounts for Sweden the accumulation of funds in the newly created second pillar are classified within the public sector. They should therefore show up as a surplus in general government accounts.

As regards Italy, where the recent pension reforms include NDC type elements, one should be cautious about drawing any simple conclusions from the above principle, even though pension expenditure as a percent of GDP is projected to fall back to its current level by 2050 , after its relatively high level in 2020-40. This fall should not lead to accepting a constant net debt target throughout the period as the transition rules give generous benefits until 2040 (Brugiavini and Galasso 2003), and it is obviously uncertain whether the system is politically sustainable, i.e. whether the decline after 2040 will really happen or whether the rules will be softened. 
ciple that all generations with the same demographic characteristics should pay the same contributions for the same benefits would not be fulfilled.

Although the results in Chapter 2 above and the more detailed applications thereafter are fairly straightforward, they have not been fully developed in the previous literature. Lindbeck and Persson (2003) note this, correctly recognising that "the scholarly debate on the pros and cons of a shift to a funded system usually does not invoke a need to frame redistribution [across generations] in terms of pension reform" (p. 98). One reason for this might be that insufficient attention has been given to analysis of population ageing as a transition process triggered by a change in demographic factors. Comparing alternative steady states with different population age structures might be deficient or even misleading, and does not give a full picture about transition between them Note also that the framework developed here allows for a continuous adjustment of parameters (automatically or by a rule) as new demographic shocks arrive.

Our framework provides alternative sets of system rules which generally imply a move to partial funding, albeit in extreme cases where all adjustment is borne by a reduction of the replacement rate and/or to an increase in retirement age. The key message is that under the assumed ageing this fund is permanent, and not merely a temporary buffer which should vanish after the current baby boom generations have left the system. The view taken here stems from the currently held population projections, and the pension system principles explained. This should be contrasted with many other simulation exercises where an ad hoc assumption is made about the fund being depleted at around the time when the new steady state is reached. Again, understanding ageing as a process of transition towards a new steady state is helpful to see that shifting permanently to a new age structure requires a thorough review of pension system rules. We have shown in this paper the principles and conditions under which the result is a permanently partially funded system.

This general conclusion can be seen in the light of the analysis which describes the 'introductory gains' given to the first generation(s) when establishing a public PAYG system as the source of a pension burden, which must, in one way or another, be shared among all succeeding generations (Sinn, 2000). Were such 'introductory gains' not given to anybody, i.e. had the system been fully actuarially fair from the very beginning, the result would have been a permanently fully funded system. We have shown that introducing the principle of fairness to a mature pure PAYG system hit by population ageing leads to a combination of adjustment of pension contributions, benefits and retirement age. Many plausible combinations lead to partial funding. The key issue is that under the revised intergenerational contract, the fertility and longevity of each generation should have an impact on the benefits derived. 
The general thrust of this paper can also be expressed, referring to many previous authors, as providing an answer to the question about a perceived 'double burden' to the transitional generation which has to finance the pensions of the currently retired and also pay an additional contribution which goes to the newly established fund. Here we show that although this burden should be considered as a problem under a stable age structure, it is only fair that, under ageing, the transition generation bears the consequences of the demographic change. This principle was presented by Sinn (2000), and applied by him to German data in Sinn (2003). Here we provide the full analytical framework to calculate the fair contribution rate and the consequent establishment of a permanent fund under a broad range of alternative assumptions on adjustments to the replacement rate and retirement age, including a transition to an NDC system. Indeed, it can be considered unjustified to put a bigger burden on the transitional generation than the one suggested by our analysis.

The framework here implicitly assumes that each generation should be held responsible for the consequences of its own fertility. Although this view could be called into question in exceptional circumstances, it seems justified in most EU countries where fertility has steadily and persistently declined.

\section{The orders of magnitude}

The 3-period model of Chapter 2 provides useful back-of-an-envelope calculations for orders of magnitude, and the simulations reported in Chapters 3-4 give more refined results, including dynamic adjustment, for alternative contribution rate, replacement rate and retirement age combinations under both DB and NDC rules.

The moderate examples for a partially pre-funded, and possibly partially privatised DB system indicate that pension fund accumulation could be $100-150$ percent of GDP, with $2 / 3$ accumulated in 30 years and the rest in 60 years. This is now the order of magnitude of pension funds in the few EU Member States which took that route in the 1960s (often establishing quasi-mandatory occupational schemes). In the NDC scenarios fund accumulation is somewhat smaller, due to the assumption that a bigger fall in the replacement rate is accepted. Were replacement rates reduced more radically in either system, funding in the pension system would be lower, but people would then have to increase their voluntary saving for retirement.

\section{Robustness of the results}

Although the analysis is based on modelling only the pension system, with a number of assumptions on exogenous variables, the results are quite robust. For example, assuming a uniform interest rate for all assets and liabilities does 
not mean that the results would be in conflict with the views of those who favour a shift towards private pension funding on the grounds that the private sector offers higher returns, and that pension funding increases total saving, which again increases total welfare (as seen by Feldstein and Liebman, 2002). If their argument holds with a stable population age structure, as they may well think, it would probably also hold under ageing and strengthen the views stemming from the current analysis, and vice versa.

The same goes for arguments for funding based on reducing the labour market distortion caused by taxes on wages, which could also apply in a situation with a stable age structure. If a pension reform assures sustainability and implements intergenerational fairness, pension contributions might be better perceived as saving for retirement than as being a pure tax. This would ease distortion in the labour market and possibly even improve compliance with contribution collection.

Therefore, the various previous arguments for (partial) funding and that presented here are mutually reinforcing. The advantage of the analysis here is that it provides guidance independently of these two and possibly other arguments, and furthermore, does not exclude extensions which take them on board.

The use of the framework for designing a pension system is not significantly hampered by uncertainty of demographic projections. Although projections covering the 50 years are used as a reference, and the illustrations cover at least 70 years to show the new steady state, uncertainty about so distant a future is not relevant. For fertility, it is the figure for the current adults which is important for the intergenerational contract for them. This figure is known for the average worker by age 40 . As fertility changes, the framework provides the rule for taking this into account. For longevity there is some genuine uncertainty as, at each point in time, it is the projection over the next 30 years which is relevant.

Most results above are robust also because it was assumed that pension rights and pensions are indexed to (average) wages (directly or via the wage bill in the NDC scenarios). This may be a reasonably good approximation of reality. An important consequence of this is that most results depend neither on the assumed underlying rate of growth of real GDP nor on inflation.

Nor do the general conclusions depend imperatively on the interest rate assumption, which reiterates the conventional view, compatible with elementary growth theory, that the interest rate exceeds by a given margin the growth of the wage bill.

Some of these additional features and modifications to the assumptions could be easily introduced to an actuarial model for making sensitivity tests and for obtaining more general results. To study broader issues about the effects on the labour market, capital formation and financial markets would naturally require 
a macroeconomic model. The actuarial model calculations on the effect of pension reform options on pension system revenue and expenditure and funding would be a valuable input to that work. It is expected that both the qualitative conclusions and the rough orders of magnitude of quantitative results in the present paper would remain intact.

\section{Framing}

A fundamental question still remains as to whether the pension system should be tailored to transfer resources from one generation to the next or whether this could happen via the general government budget. We took the logic of the pure PAYG pension system under a constant age structure as the starting point and showed that the same logic generally leads to partial funding under ageing. Lindbeck and Persson (2003) note that "redistribution in favour of future generations ... can be accomplished by ordinary fiscal measures [i.a. measures leading to debt reduction], quite outside the realm of pension reform", while the pension system is often suggested to be harnessed for this purpose. They offer as a possible answer that "pension reform is a way of framing policies that may otherwise be politically difficult to achieve" (pp. 105-106). They seem to suggest the following: if public sector net debt is to be reduced to ease the burden left for future generations, it makes it politically more acceptable if the public pension system rules are revised so that it produces a surplus, which, other revenues and expenditures being equal, then leads to a reduction of public debt.

Based on the analysis here the reasoning may also read the other way round: the rules of the public pension system must be revised, based on the own purposes and logic of the system, including intergenerational fairness, leading to accumulation of assets; these assets should not be lent for current consumption to the other parts of the general government as this would do away with the key purpose of the pension reform; the surplus in the pension system should therefore be entered into the budget balance and debt targets for the whole general government sector.

While somewhat obvious perhaps, it is still advisable to add that public investment can also be a vehicle to transfer wealth to the next generation. This could be easily inserted into the current framework. However, if the trend over the past three decades continues, public investment will merely maintain the public-capital-stock-toGDP ratio, so that no ageing-related resource transfers will take place via this route. Thus, to frame the pension reforms and public sector balances it is sufficient to look only into the financial items, notably public debt reduction.

Putting pension reforms into a correct frame is essential as they always take place in a policy context where the views and visions need to extend over not only election cycles but even over a generation. Economic analysis can provide the time paths for 
the key variables to comply with the set purposes of public policy. This should help to address the pertinent questions about commitment and 'ownership' of the reform ideas, and their explanation to the general public.

\section{References}

Aaron, H. (1966), "Social insurance paradox", Canadian Journal of Economics and Political Science XXXII(3), 371-374.

Boeri, T., A. Börsch-Supan and G. Tabellini (2001), "Would you like to shrink the welfare state? A survey of European citizens", Economic Policy (32).

Boeri, T., A. Börsch-Supan and G. Tabellini (2002), "Pension Reforms and the Opinions of European Citizens", American Economic Review 92.

Börsch-Supan, A. and C. Wilke (2003), "The German Public Pension System: How it Was, How it Will Be", Conference paper, Michigan, August.

Breyer, F. (1989), "On the International Pareto Efficiency of Pay-as-you-go Financed Pension Systems", Journal of Institutional and Theoretical Economics (JITE) 145, 643-658.

Breyer, F. (2001), "Why Funding is not a Solution to the "Social Security Crisis”, DIW Discussion Papers No. 254.

Breyer, F. and M: Kifmann (2003), "Incentives to retire later - a solution to the social security crisis?", manuscript.

Brugiavini, A. and V. Galasso (2003), "The social security reform process in Italy: where do we stand?", Workshop paper, Michigan, July.

Brugiavini, A., F. Peracchi and D.A. Wise (2002), "Pensions and Retirement Incentives. A tale of three countries: Italy, Spain and the USA", Giornale degli Economisti e Annali di Economia 61(M. 29, 131-169.

Bundersministerium für Gesundheit und Soziale Sicherung (2003), "Achieving Financial Sustainability for the Social Security Systems", Report of the Commission chaired by B. Rürup.

Cass, D. (1965), "Optimum Growth in an Aggregative Model of Capital Accumulation", Review of Economic Studies 32, 233-240.

Diamond, P. (1996), "Proposals to Restructure Social Security", Journal of Economic Perspectives 10(3), 67-88. 
Disney, R. (2000), "Crises in Public Pension Programmes in OECD: what are the reform options?", Economic Journal 110, F1-F23.

Economic Policy Committee (2001), "Budgetary challenges posed by ageing populations", October; EPC is a committee of the European Union; the report is available at

http://europa.eu.int/comm/economy_finance/epc/documents/ageing_en.pdf

Esping-Andersen, G., D. Gallie, A. Hemerijckn and J. Myles (2002), Why we need a New Welfare State, Oxford University Press, Oxford.

European Commission (2002), "The EU Eeonomy 2002 Review", European Economy.

Feldstein, M. and J.B. Liebman (2002), "Social Security", in A.J. Auerbach and M.S. Feldstein (eds.), Handbook of Public Economics, Vol. 4, North Holland, Amsterdam and New York, 2245-2324.

Fenge, R., S. Übelmesser and M. Werding (2002), "Second-best Properties of Implicit Social Security Taxes: Theory and Evidence", CESifo Working Paper No. 743.

Fenge, R. and M. Werding (2003a), "Ageing and the Tax Implied in Public Pension Schemes: Simulations for Selected OECD Counties", CESifo Working Paper No. 841.

Fenge, R. and M. Werding (2003b), "Ageing and Fiscal Balances Across Generations: Concepts of Measurement", CESifo Working Paper No. 842.

Holzmann, R. (1998), "Financing the Transition to Multipillar", Social Protection Discussion Paper Series No. 98 9, December 1998, World Bank.

Holzmann, R. (1999), "The World Bank's Approach to Pension Reform”, September 1999, World Bank web-site.

Kifmann, M. and D. Schindler (2001), "Smoothing the Implicit Tax Rate in a Pay-as-you-go Pension System", FinanzArchiv 57, 261-283.

Lindbeck, A. (2001), "Pensions and Contemporary Socioeconomic Change", The Research Institute of Industrial Economics (IUI) Working Papers, No. 548.

Lindbeck, A. and M. Persson (2003), "The Gains from Pension Reform", Journal of Economic Literature XLI(1), 74-112.

Marè, M. and G. Pennisi (2004), "Financial Constraints and Policy Options: the Pension Reform Process in Italy, and its Relevance to Eastern Europe", in OECD (2004). 
Musgrave, R.A. (1986), "Public Finance in a Democratic Society", in Volume II "Fiscal Doctrine, Growth and Institutions", Chapter 7, Harvester Press.

OECD (2004), Reforming Public Pensions, Sharing the Experiences of Transition and OECD Countries, Organisation for Economic Co-operation and Development, Paris, 2004.

Oksanen, H. (2001a), "A Case for Partial Funding of Pensions with an Application to the EU Candidate Countries", European Economy, Economic Papers, No 149, Directorate-General for Economic and Financial Affairs of the European Commission, http://europa.eu.int/comm/economy finance/publications_en.htm, also CESifo Working Paper No. 466 (http://www.CESifo.de).

Oksanen, H. (2001b), "Pension Reforms for Sustainability and Fairness", $C E-$ Sifo Forum, Winter 2001, 12-18.

Oksanen, H. (2002) "Pension Reforms: key issues illustrated with an actuarial model", European Economy, Economic Papers No 174, Directorate-General for Economic and Financial Affairs, European Commission, at http://europa.eu.int/comm/economy_finance/publications_en.htm

Oksanen, H. (2003) "Population ageing and public finance targets", No 196, European Economy, Economic Papers, Directorate-General for Economic and Financial Affairs, European Commission, at http://europa.eu.int/comm/economy_finance/publications_en.htm

Orszag, P.R. and J.E. Stiglitz (2001), "Rethinking Pension Reform: Ten Myths About Social Security Systems", in R. Holzmann and J.E. Stiglitz (eds.), New ideas about old age security, World Bank, Washington, 17-56.

Palmer, E. (2000), "The Swedish Pension Reform Model: Framework and Issues", The World Bank website.

Samuelson, P.A. (1958), "An exact consumption-loan model of interest with or without the social contrivance of money", Journal of Political Economy LXVI, 467-482.

Schokkaert, E. and P. Van Parijs (2003), "Social Justice and the Reform of Europe's Pension Systems", Journal of European Social Policy 13(3), 245 -263 .

Settergren, O. (2001a), "The Automatic Balance Mechanism of the Swedish Pension System - a non-technical introduction", Wirtschafts Politische Blät$\operatorname{ter}(4), 339-349$. 
Settergren, O. (2001b), "Two Thousand Five Hundred Words on the Swedish Pension Reform", paper presented at the workshop on Pension Reform, German Embassy, Washington D.C., manuscript.

Simonovits, A. (2003), "Designing Optimal Flexible Rules for Early Retirement", Journal of Pension Economics and Finance 2(3).

Sinn, H.-W. (2000), "Why a Funded System is Useful and Why it is Not Useful". International Tax and Public Finance 7, 389-410.

Sinn, H.-W. (2003), "The Crisis of Germany's Pension Insurance System and How It Can Be Resolved", in S. Cnossen and H.-W. Sinn (eds.), Public Finance and Public Policy in the New Century, CESifo Seminar Series.

The Economist, Supplement, Pensions, $16^{\text {th }}$ February, 2002.

The Swedish Pension System Annual Report 2002, Stockholm, National Social Insurance Board, RFV.

The World Bank (1994), "Averting the Old Age Crisis, Policies to Protect the Old and Promote Growth", Oxford and New York, Oxford University Press.

UN Economic Commission for Europe (1999), Economic Survey of Europe, 3/1999, New York and Geneva.

Valdes-Prieto, S. (2000), "The Financial Stability of Notional Account Pensions", Scandinavian Journal of Economics 102(3), 395-417.

Vanovska, I. (2004), "Pension reform in Latvia: achievements and challenges", in OECD (2004).

Williamson, J. B. (2001), "Future Prospects for Notional Defined Contribution Schemes", CESifo Forum, Winter, 19-24. 
Settergren, O. (2001b), "Two Thousand Five Hundred Words on the Swedish Pension Reform", paper presented at the workshop on Pension Reform, German Embassy, Washington D.C., manuscript.

Simonovits, A. (2003), "Designing Optimal Flexible Rules for Early Retirement", Journal of Pension Economics and Finance 2(3).

Sinn, H.-W. (2000), "Why a Funded System is Useful and Why it is Not Useful". International Tax and Public Finance 7, 389-410.

Sinn, H.-W. (2003), "The Crisis of Germany's Pension Insurance System and How It Can Be Resolved", in S. Cnossen and H.-W. Sinn (eds.), Public Finance and Public Policy in the New Century, CESifo Seminar Series.

The Economist, Supplement, Pensions, $16^{\text {th }}$ February, 2002.

The Swedish Pension System Annual Report 2002, Stockholm, National Social Insurance Board, RFV.

The World Bank (1994), "Averting the Old Age Crisis, Policies to Protect the Old and Promote Growth", Oxford and New York, Oxford University Press.

UN Economic Commission for Europe (1999), Economic Survey of Europe, 3/1999, New York and Geneva.

Valdes-Prieto, S. (2000), "The Financial Stability of Notional Account Pensions", Scandinavian Journal of Economics 102(3), 395-417.

Vanovska, I. (2004), "Pension reform in Latvia: achievements and challenges", in OECD (2004).

Williamson, J. B. (2001), "Future Prospects for Notional Defined Contribution Schemes", CESifo Forum, Winter, 19-24. 